\title{
Appendix to: Managing Episodic Volunteers in Free/Libre/Open Source Software Communities
}

\author{
Ann Barcomb, Klaas-Jan Stol, Brian Fitzgerald and Dirk Riehle
}

\section{APPENDIX A \\ PARTICIPANT Details}

Table 1 details our study participants by country of origin, country of residence, and the contribution types they engage in.

\section{APPENDIX B \\ Description of Communities Represented}

We include a brief description of the communities our participants are engaged in, which are listed in alphabetical order.

\section{B.1 Anonymous community}

$\mathrm{CM}_{1}$ preferred not to have their community named. The project was initiated in 2000. It has a well-established codebase which is licensed under GPL v3, consisting of more than 30,000 commits made by about 200 developers. New stable releases are made twice a year. The project's primary programming language is Perl.

\section{B.2 Apache}

Website: http://www.apache.org

The Apache Software Foundation (ASF) supports the Apache community of open source software projects. The ASF is allvolunteer and develops and stewards more than 350 projects and initiatives. The original Apache HTTP server is written in $\mathrm{C}$.

$\mathrm{CM}_{2}$, who is engaged at the foundation level, described the community this way: "Our mission is to support the creation of Open Source software at no charge under the Apache License, by providing project access to our resources where likeminded communities can flourish and produce and release software according to our guidelines and under our legal umbrella."

\section{B.3 CHAOSS}

Website: https://chaoss.community

The Community Health Analytics Open Source Software (CHAOSS) community is a part of the Linux Foundation. It is a collaboration between academics and practitioners. The metrics committee aims to define implementation-agnostic metrics to evaluate open source communities' health and sustainability. Thus the project concerns standards; implementations may be written in any programming language.
It is a small community, with about 15 people contributing each month.

In the words of $\mathrm{CM}_{4}$ : "The CHAOSS community aims to understand open source community health. We have two committees focusing on two aspects of health. The metrics committee I'm involved with managing it - standardizes metrics and aims to fully understand how they inform health, can be used, and gamed. The software committee builds software to generate health metrics for communities."

\section{B.4 ChakraLinux}

Website: https://chakralinux.org

ChakraLinux is a GNU/Linux distribution which focuses on technical simplicity and KDE and Qt technologies. It was founded in 2006 and was first released in 2008. The Linux kernel is written primarily in $\mathrm{C}$. According to $\mathrm{CM}_{3}$, around 50-100 people are active on a monthly basis in advancing ChakraLinux.

ChakraLinux does not schedule release dates, but uses a "half-rolling release" system where core packages are frozen and only updated to fix security issues. After they have been tested, they are moved to the permanent repository (approximately twice a year). Other applications are updated on a rolling release model with immediate availability.

\section{B.5 Debian}

Website: https://www.debian.org

Debian is a free software operating system. The first release was made in 1993 and it currently contains over 50,000 packages. Debian has about a thousand active developers. It is governed by an elected project leader who serves a one year term. The Linux kernel is written primarily in C.

The Debian project uses a vetting process for developers which seeks to establish not only participants' technical competence but also motivation and understanding of the project's principles, which are described in the 'Social Contract.' $\mathrm{CM}_{16}$ and $\mathrm{CM}_{5}$ were the Debian community mentors participating in our study.

\section{B.6 Drupal}

Website: https://www.drupal.org

Drupal is a content-management framework. It is a large community. $\mathrm{CM}_{6}$ described the Drupal community as " $a$ huge international community with thousands of contributors to 
TABLE 1

Participants by country and contribution type

\begin{tabular}{|c|c|c|c|c|c|c|c|c|c|c|c|c|}
\hline \multirow{2}{*}{ ID } & \multirow{2}{*}{ Country of Origin } & \multirow{2}{*}{ Country of Residence } & \multicolumn{10}{|c|}{ Contribution types } \\
\hline & & & SC & Do & $\operatorname{Tr}$ & Dn & $\mathrm{Su}$ & $\mathrm{Eg}$ & $\mathrm{Me}$ & $\mathrm{CM}$ & Es & Ec \\
\hline $\mathrm{CM}_{1}$ & USA & USA & & $\checkmark$ & & & $\checkmark$ & $\checkmark$ & & $\checkmark$ & $\checkmark$ & $\checkmark$ \\
\hline $\mathrm{CM}_{2}$ & Kenya & USA & $\checkmark$ & $\checkmark$ & $\checkmark$ & $\checkmark$ & $\checkmark$ & $\checkmark$ & $\checkmark$ & $\checkmark$ & $\checkmark$ & $\checkmark$ \\
\hline $\mathrm{CM}_{3}$ & Cyprus & Cyprus & $\checkmark$ & $\checkmark$ & $\checkmark$ & $\checkmark$ & $\checkmark$ & $\checkmark$ & $\checkmark$ & $\checkmark$ & $\checkmark$ & $\checkmark$ \\
\hline $\mathrm{CM}_{4}$ & Germany & USA & $\checkmark$ & $\checkmark$ & & & $\checkmark$ & $\checkmark$ & $\checkmark$ & $\checkmark$ & & \\
\hline $\mathrm{CM}_{5}$ & Italy & France & $\checkmark$ & $\checkmark$ & & & & $\checkmark$ & $\checkmark$ & $\checkmark$ & $\checkmark$ & $\checkmark$ \\
\hline $\mathrm{CM}_{6}$ & Spain & Spain & $\sqrt{ }$ & & $\checkmark$ & $\checkmark$ & & & & $\sqrt{ }$ & $\checkmark$ & $\checkmark$ \\
\hline $\mathrm{CM}_{7}$ & USA & Czech Republic & $\checkmark$ & $\checkmark$ & & & & & & $\checkmark$ & $\checkmark$ & $\checkmark$ \\
\hline $\mathrm{CM}_{8}$ & Singapore & Singapore & & & & & & $\checkmark$ & & $\checkmark$ & $\checkmark$ & $\checkmark$ \\
\hline $\mathrm{CM}_{9}$ & Brazil & Brazil & & & $\checkmark$ & $\checkmark$ & & & & $\checkmark$ & & \\
\hline $\mathrm{CM}_{10}$ & South Korea & Germany & & & $\checkmark$ & & & $\checkmark$ & $\checkmark$ & $\checkmark$ & & \\
\hline $\mathrm{CM}_{11}$ & USA & USA & $\checkmark$ & $\checkmark$ & & & $\checkmark$ & $\checkmark$ & & $\checkmark$ & $\checkmark$ & $\checkmark$ \\
\hline $\mathrm{CM}_{12}$ & Romania & Romania & & $\checkmark$ & & & $\checkmark$ & $\checkmark$ & & $\checkmark$ & & \\
\hline $\mathrm{CM}_{13}$ & Uganda & Uganda & $\checkmark$ & $\checkmark$ & $\checkmark$ & $\checkmark$ & $\checkmark$ & $\checkmark$ & $\checkmark$ & $\checkmark$ & $\checkmark$ & $\checkmark$ \\
\hline $\mathrm{CM}_{14}$ & India & India & $\checkmark$ & & & & $\checkmark$ & $\checkmark$ & $\checkmark$ & $\checkmark$ & $\checkmark$ & \\
\hline $\mathrm{CM}_{15}$ & Ireland & Japan & & & & & & $\checkmark$ & & $\checkmark$ & $\checkmark$ & $\checkmark$ \\
\hline $\mathrm{CM}_{16}$ & USA & USA & $\checkmark$ & & & & & & & $\checkmark$ & & \\
\hline $\mathrm{CM}_{17}$ & Hungary & Hungary & $\checkmark$ & $\checkmark$ & & & & $\checkmark$ & $\checkmark$ & $\checkmark$ & $\checkmark$ & \\
\hline $\mathrm{CM}_{18}$ & Australia & Australia & & $\checkmark$ & & & & & $\checkmark$ & $\checkmark$ & & \\
\hline $\mathrm{CM}_{19}$ & UK & UK & $\checkmark$ & $\checkmark$ & & $\checkmark$ & & $\checkmark$ & $\checkmark$ & $\checkmark$ & $\checkmark$ & $\checkmark$ \\
\hline $\mathrm{CM}_{20}$ & France & France & $\checkmark$ & $\checkmark$ & $\checkmark$ & & $\checkmark$ & $\checkmark$ & $\checkmark$ & $\checkmark$ & $\checkmark$ & \\
\hline $\mathrm{CM}_{21}$ & Brazil & Argentina & & & & & & $\checkmark$ & $\checkmark$ & $\checkmark$ & $\checkmark$ & \\
\hline $\mathrm{CM}_{22}$ & Tunisia & Tunisia & & & $\checkmark$ & & $\checkmark$ & $\checkmark$ & $\checkmark$ & $\checkmark$ & $\checkmark$ & \\
\hline $\mathrm{CM}_{23}$ & Peru & Peru & $\checkmark$ & $\checkmark$ & $\checkmark$ & & $\checkmark$ & $\checkmark$ & $\checkmark$ & $\checkmark$ & $\checkmark$ & $\checkmark$ \\
\hline $\mathrm{CM}_{24}$ & Ukraine & UK & & & & & & $\checkmark$ & $\checkmark$ & $\checkmark$ & $\checkmark$ & \\
\hline
\end{tabular}

Legend: Source code (SC), Documentation (Do), Translation (T), Design (Dn), Support (Su), Evangelizing (Eg), Mentoring (Me), Community management (CM), Events (Es), Economics (Ec)

one of the most used CMS of the web. There are over 1 milion users at Drupal.org, with more than 100,000 active users. It is mainly used for professional purposes, so not only individuals are part of the community: companies too, giving time to contribute to the employers or sponsoring Drupal events."

The Drupal community operates with a number of working groups. The project founder, Dries Buytaert, has final authority on decisions. Drupal is written in PHP.

\section{B.7 Fedora}

Website: https://getfedora.org

Fedora project community and sponsored primarily by Red Hat. It was launched in 2003. The Linux kernel is written primarily in C. $\mathrm{CM}_{8}$ described the governance structure: "Development of project is headed by steering community heads. For engineering, there's FESCo. There's also the main steering community - Fedora council. Elections take place and are democratica person being part of Red Hat doesn't mean that he/she will stand a higher chance of being elected. Red Hat simply has employees dedicated to Fedora Project (just like how they have employees dedicated to Openshift and Kubernetes; of which Kubernetes is owned by Google.)." $\mathrm{CM}_{7}$ was another Fedora community mentor who participated in our study.
Fedora has an estimated 1.2 million users. It has a relatively short release cycle, with two releases a year. Each release is only supported for 1 month after the two subsequent versions have been released.

\section{B.8 Joomla!}

Website: https://www.joomla.org

Joomla! is a content management system. It has been downloaded over 97 million times and is estimated to be the second most common content management system in use. It is written in PHP. It was first released in 2005. Joomla! is governed by a board of directors.

$\mathrm{CM}_{9}$ described how inclusivity has been important aspect of the Joomla! community: "In my city, a smaller community with lightning talks about Joomla and about PHP code, with focus in women and transgender people. The guys contribute with knowledge and are encouraged to live in harmony and respect with them."

\section{B.9 KDE}

Website: https://www.kde.org

$\mathrm{KDE}$ is a free software community which creates a number of tools, most notably the Plasma Desktop, written in $\mathrm{C}++$, 
which is the default desktop environment for a number of Linux distributions. KDE is a large community, with more than 2,500 active contributors. KDE is known for being a volunteer-oriented community, although paid developers also participate. The overall direction is set by the KDE Core Team, which consists of developers who have made significant contributions over a long period of time.

$\mathrm{CM}_{11}$ described being a member of the Community Working Group in KDE as being a "gardener of the community": "If we personally can't handle the problem for whatever reason, one or two of the others will step up and help out. Fortunately problems don't arise often, because they are very emotionally draining when they do. So this job is by its nature episodic." $\mathrm{CM}_{10}$ participates in the Korean KDE community, working to maintain ties between Korean KDE enthusiasts and the broader community, and addressing localization issues.

\section{B.10 Kubuntu}

Website: https://kubuntu.org

Kubuntu is a variant of the Ubuntu operating system which uses the KDE Plasma Desktop. Kubuntu development is led by community contributors. The Linux kernel is written primarily in $\mathrm{C}$.

$\mathrm{CM}_{11}$ described the release process within Kubuntu: "The RM [Release Manager] is in charge of the team of folks who ensure that all the newest applications are built, tested and uploaded in time for the various releases and the milestones leading up to that release. We coordinate testing, create the necessary documentation and publicity for the process." 11also explained governance: "The Council's official duty is to recruit and admit new Kubuntu Members. In addition, we're often asked for advice and consent for various issues which touch governance and try to provide leadership to the team. Terms are for two years, and sometimes people do disappear during or after their terms."

\section{B.11 Linux Mint}

Website: https://linuxmint.com

Linux Mint is a community-driven GNU/Linux distribution based on Debian and Ubuntu. The Linux kernel is written primarily in C. Development started in 2006. Individuals and companies can act as donors, sponsors, and partners in the distribution. $\mathrm{CM}_{12}$ participated in the study as a Linux Mint community member.

Linux Mint does not have a strict release schedule but releases new versions when they are ready. It is described as community-driven, and encourages feedback from the community.

\section{B.12 Mozilla}

Website: https://www.mozilla.org

The Mozilla Foundation is a charitable organization. The Mozilla community has hundreds of core contributors, thousands of active contributors, and tens of thousands of casual contributors. Mozilla describes its goal as ensuring that the internet is a global public resource, open and accessible to all. Its flagship project, Firefox, is written in $\mathrm{C}$ and $\mathrm{C}++$.

$\mathrm{CM}_{13}$ and $\mathrm{CM}_{14}$ participated in our study as Mozilla community contributors. $\mathrm{CM}_{14}$ described the community structure of Mozilla: "For Mozilla global community, the structure is divided region wise example, Mozilla Brazil, Mozilla UK, Mozilla Taiwan etc. I am a part of Mozilla community as a whole [not just the Mozilla India community]."

\section{B.13 NextCloud}

Website: https://nextcloud.com

NextCloud is a collection of client-server software for file hosting. It was founded in 2016 as a fork of ownCloud. ownCloud has both a free and a commercial version, while NextCloud has only a community version. It is written in PHP. $\mathrm{CM}_{10}$ participated in maintaining translations for ownCloud and NextCloud.

NextCloud has grown rapidly, and had over 100,000 downloads in 2017. NextCloud contains code from about 1,000 people, of whom about 100 are regular contributors.

\section{B.14 OSGeo-Live}

Website: https://live.osgeo.org

OSGeo-Live is a software distribution of about 50 geospatial open source applications, along with data and documentation. Applications are written in a variety of programming languages. Development started in 2008. It is governed by a Project Management Committee.

$\mathrm{CM}_{18}$ described the community structure: "Focused, periodic contributions are provided by each project represented on OSGeo-Live, and by each language community who translate documentation. As such, OSGeo-Live is both a community and a community of communities. While OSGeo-Live has occasionally attracted sponsored contributors, and does currently have some infrastructure services provided by the OSGeo Foundation and Universities, it is almost entirely run by volunteer labour."

\section{B.15 OpenChain Project}

Website: https://www.openchainproject.org The OpenChain Project strives to increase trust in open source by simplifying open source license compliance and making it more consistent. The OpenChain Specification provides a core set of requirements every quality compliance program must satisfy, while OpenChain Curriculum provides education on open source processes and solutions. OpenChain Conformance allows organizations to indicate that they adhere to the requirements. The reference implementation of OpenChain is written in C\#.

$\mathrm{CM}_{15}$ described OpenChain participation: "I run the OpenChain Project with a diverse community of company representatives, NGO representatives and individual participants. Our goal is to define the key requirements of a quality open source compliance program for use throughout the global supply chain."

\section{B.16 OpenStack}

Website: https://www.openstack.org

$\mathrm{CM}_{17}$ summarized the project: "OpenStack is an open source project producing the open standard cloud computing platform for both public and private clouds. A new version of the software is released every half year as the result of the collaborative efforts of over 2500 developers around the globe per cycle. The project is managed by the OpenStack Foundation and has over 600 supporting companies." OpenStack was started in 2010 as a 
joint project of Rackspace Hosting and NASA. OpenStack uses Python.

$\mathrm{CM}_{16}$ also participated in our research as an OpenStack community mentor.

\section{B.17 Perl}

Website: https://www.perl.org

Perl is a programming language which was first launched in December 1987. It is written in C. The Perl Foundation is responsible for advancing the Perl programming language and carries the legal responsibility for both Perl 5 and Raku (formerly Perl 6). Perl 5 has over 185,000 libraries, which were written by more than 13,000 authors.

$\mathrm{CM}_{19}$, whose focus is the repository for Perl libraries, CPAN, described communities within Perl: "There are three parts to what I consider 'my community'. The second and third are subsets of the first. The broader set is the 'Perl community': people who program in Perl, use Perl in some way, whether for pleasure or work, and who may or may not share their results. The subset is CPAN authors, those members of the Perl community who have shared one or more things as open source, on CPAN. And helping people from the first set gain membership of this second one. A further subset I'm active in is the CPAN Toolchain developers: those members of the Perl community who develop the tools, services, and specs used by CPAN authors."

\section{B.18 PostgreSQL}

Website: https://www.postgresql.org

PostgreSQL is an open source relational database management system. It is developed by the PostgreSQL Global Development Group, which is a diverse group of companies and individual contributors. Releases are made about once a year. It is written in C.

PostgreSQL has over 400 developers and "as with other open source projects, of course, we depend on hundreds of community members for documentation, translations, advocacy, conferences, website development, infrastructure, and peer-to-peer support." (PostgreSQL website, accessed 2019-01-10). CM 20 participated in our research as a PostgreSQL community mentor.

\section{B.19 Python}

Website: https://www.python.org

Python is a programming language which was first released in 1991. It is widely used in web development and data science. It is implemented in C. $\mathrm{CM}_{21}$ described the community: "Community to me is a set of people who help each other with respect to technology. It also has a common purpose as a specific type of technology."

Until 2018, Python was led by the Benevolent Dictator for Life, Guido van Rossum. Currently Python is undergoing a governance model selection process. The Python Software Foundation is the non-profit behind the language.

\section{B.20 RDO}

Website: https://www.rdoproject.org

$\mathrm{RDO}$ is a community of people deploying OpenStack on CentOS, Fedora, and RHEL operating systems. RDO is an open source project for creating Infrastructure as a Service (IaaS) on standard hardware. It is not a fork of OpenStack but a community which packages OpenStack. OpenStack itself is written in Python. $\mathrm{CM}_{2}$ contributed to our study from the perspective of the RDO community manager.

Many RDO contributors are Red Hat employees, but there are also participants working for other companies or volunteering. Most contributors participate several times each release, but do not work on the project full-time.

\section{B.21 Ubuntu}

Website: https://www.ubuntu.com

$\mathrm{CM}_{22}$ described the Ubuntu community: "Ubuntu is a GNU/Linux distribution. The name comes from the philosophy of 'ubuntu', or 'humanity to others'/'I am what I am because of who we all are'. Ubuntu is committed to free software principles. It was first released in 2004. Ubuntu is funded through a portfolio of services provided by Canonical Ltd." $\mathrm{CM}_{23}$ also participated in our study by providing a perspective from the Ubuntu community.

The community processes of Ubuntu are overseen by the Community Council. The Ubuntu Technical Board manages the technical direction of Ubuntu. Although the community strives to operate on consensus, some matters are handled by vote, and ultimately Mark Shuttleworth, the project sponsor, can become involved. The Linux kernel is written in C.

\section{B.22 Women Who Code}

Website: https://www.womenwhocode.com

$\mathrm{CM}_{24}$ summarized the community: Women Who Code is a global non-profit organization dedicated to inspiring women to excel in technology careers. The organisation includes 50,000 people in 20 countries. Kyiv branch has been launched in January 2017 and already has 800 members, including both women and allies." The organization pursues its objectives by educating companies to hire, retain, and promote talented women; developing role models; and building a global community of networking and mentorship.

Women Who Code is not, strictly speaking, a FLOSS community because it is not involved in the creation of FLOSS software. However, because its mission closely relates to software development, and FLOSS communities such as Mozilla have embraced a broader social mission, we included the community in the study to increase the observations of event organization and mentoring activities.

\section{APPENDIX C CODE SYSTEM}

Table 2 depicts the codes which made up the final code system. Predefined codes were used to sampling criteria. Expertise and Location were applied based on the participant. More than one code per category could be applied, as shown in Table 1. Project was also part of the sampling criteria, but because participants wrote about multiple projects, including one not part of this study (Streetlights Uganda), coding was based on both the text and the participant. The codes associated with Components were deductively inspired by the patterns community. The remaining codes were inductively derived from the data. 
TABLE 2. The code system

\begin{tabular}{|c|c|c|}
\hline Category & Sub-category & Code \\
\hline Expertise & & $\begin{array}{l}\text { Design } \\
\text { Documentation } \\
\text { Economics } \\
\text { Evangelizing } \\
\text { Events } \\
\text { Mentoring } \\
\text { Source code } \\
\text { Support } \\
\text { Translation }\end{array}$ \\
\hline \multirow{6}{*}{ Location } & Africa & $\begin{array}{l}\text { Kenya } \\
\text { Tunisia } \\
\text { Uganda }\end{array}$ \\
\hline & Asia & $\begin{array}{l}\text { India } \\
\text { Japan } \\
\text { Singapore } \\
\text { S. Korea }\end{array}$ \\
\hline & & Australia \\
\hline & Europe & $\begin{array}{l}\text { Cyprus } \\
\text { Czech R. } \\
\text { France } \\
\text { Germany } \\
\text { Hungary } \\
\text { Ireland } \\
\text { Italy } \\
\text { Romania } \\
\text { Spain } \\
\text { UK } \\
\text { Ukraine }\end{array}$ \\
\hline & N. America & USA \\
\hline & S. America & $\begin{array}{l}\text { Argentina } \\
\text { Brazil } \\
\text { Peru }\end{array}$ \\
\hline Project & & $\begin{array}{l}\text { Apache } \\
\text { (Anon) } \\
\text { CHAOSS } \\
\text { Chakra } \\
\text { Debian } \\
\text { Drupal } \\
\text { Fedora } \\
\text { Joomla! } \\
\text { KDE } \\
\text { Kubuntu } \\
\text { Mint } \\
\text { Mozilla } \\
\text { NextCloud } \\
\text { OSGeoLive } \\
\text { OpenChain } \\
\text { OpenStack } \\
\text { Perl } \\
\text { PostgreSQL } \\
\text { Python } \\
\text { RDO } \\
\text { Streetlights } \\
\text { Ubuntu } \\
\text { WWC }\end{array}$ \\
\hline \multirow[t]{3}{*}{ Components } & & $\begin{array}{l}\text { Caveat } \\
\text { Context } \\
\text { Practice } \\
\text { Problem } \\
\text { Result } \\
\text { SeeAlso } \\
\text { Suggestion }\end{array}$ \\
\hline & & Strategy \\
\hline & & $\begin{array}{l}\text { Def. of quality } \\
\text { Define success } \\
\text { Diversity } \\
\text { Get sponsorship }\end{array}$ \\
\hline
\end{tabular}

\begin{tabular}{|c|c|c|}
\hline Category & Sub-category & Code \\
\hline & & $\begin{array}{l}\text { In-person meet } \\
\text { Longer cycles } \\
\text { Manage delivery } \\
\text { Public decisions } \\
\text { Sponsorship mngmt } \\
\text { Sponsorship money } \\
\text { Vision }\end{array}$ \\
\hline & Onboarding & $\begin{array}{l}\text { Choice of tasks } \\
\text { Contrib constraints } \\
\text { Intro events } \\
\text { Junior jobs } \\
\text { Maintenance } \\
\text { Screen contrib } \\
\text { Task mgmt }\end{array}$ \\
\hline & Prep & $\begin{array}{l}\text { Active comm } \\
\text { Appropriate tasks } \\
\text { Continual entry } \\
\text { Crowdsource tasks } \\
\text { Deadlines } \\
\text { Detail task } \\
\text { Dev env } \\
\text { Doc activity } \\
\text { Document prac } \\
\text { Educate sponsors } \\
\text { List activity } \\
\text { Modularity } \\
\text { One-off tasks } \\
\text { Prog meet } \\
\text { Respond } \\
\text { Small events } \\
\text { Soc media team } \\
\text { Succ stories } \\
\text { Templates } \\
\text { Working group }\end{array}$ \\
\hline & Retention & $\begin{array}{l}\text { Ack contrib } \\
\text { Ack people } \\
\text { Comm commit } \\
\text { Listen sugg } \\
\text { Milestones } \\
\text { Promote EV } \\
\text { Promotion path } \\
\text { Pub rel schedule } \\
\text { Public praise } \\
\text { Reward } \\
\text { Rotate focus } \\
\text { Soc connect } \\
\text { Stay in touch } \\
\text { Unofficial proj }\end{array}$ \\
\hline & Working & $\begin{array}{l}\text { Automate help } \\
\text { Automate quality } \\
\text { Contrib context } \\
\text { Expectations } \\
\text { Force quit } \\
\text { Key contrib } \\
\text { Mandatory docs } \\
\text { Mentor quality } \\
\text { Newbies mentor } \\
\text { Ok quit } \\
\text { Pls quit } \\
\text { Reject poor quality } \\
\text { Remind }\end{array}$ \\
\hline & Exclusion & $\begin{array}{l}\text { Cannot discuss } \\
\text { Cannot lead } \\
\text { No recognition } \\
\text { No rewards }\end{array}$ \\
\hline & Knowledge & $\begin{array}{l}\text { EV unkwn opportunity } \\
\text { EV unkwn updates } \\
\text { EV unkwn vision }\end{array}$ \\
\hline
\end{tabular}

Concerns

Governance 


\begin{tabular}{lll}
\hline Category & Sub-category & Code \\
\hline & Mismatch \\
& Unkwn EV avail \\
\cline { 2 - 3 } & Appropriate tasks \\
& Processes & No EV strategy \\
& No EV support \\
\cline { 2 - 2 } & Cost supervise \\
& EV Wanted & EV timeliness \\
& EV work quality \\
\hline
\end{tabular}

\section{APPENDIX D CONCERNS}

This appendix contains a description of all 16 concerns identified by community managers about EV. Concerns are grouped by broad categories.

\section{D.1 Knowledge Exchange}

Concern: 1.C Episodic contributor lacks knowledge of developments during absences

In a rapidly changing or large community, it can be difficult for participants to retain an overview of key discussions and important decisions. It becomes an even greater challenge when a person is not engaging with the community regularly, but is participating in spurts. A person who understands only some of the community's recent history will have difficulty joining in discussions and sub-projects which rely on that knowledge.

Concern: 2.C Episodic contributor lacks awareness of opportunities to contribute

Communicating opportunities to get involved in a way that reaches episodic contributors is a concern for communities, especially when the people who are aware of tasks which could be done episodically do not enjoy outreach activities.

Concern: 3.C Community lacks knowledge of availability of episodic contributors

In the context of event organization or other situations where it is essential to have a volunteer available for a specific task at a particular time, organizers find it challenging to not have a good understanding of which contributors will be available.

Concern: 4.C Episodic contributor lacks understanding of project vision

Episodic contributors may not understand the overall project vision, and thus be more likely to make proposals which don't align with community goals, or to submit work which either cannot be used or which requires extensive work from others to be aligned with the community's vision and project roadmap.

Concern: 5.C Episodic contributor and community have mismatched expectations

When community members offer guidance to new participants, they often do so out of the expectation that the newcomers will become habitual contributors. However, a newcomer may not have this intention. Mismatched expectations about the commitment of a newcomer and the amount of effort that person will put into the project can lead to frustration and discouragement among habitual contributors involved in mentoring.

\section{D.2 Suitability of Episodic Contributors for the Work}

Concern: 6.C Episodic contributor quality of work is insufficient

Contributors who are less invested in the project and contribute in a 'drive-by' fashion are often not interested in working to improve their contribution so that it can be readily used. Often, this work falls on other people, or is not done at all.

Concern: 7.C Episodic contributor's timeliness and completion of work is poor

Episodic contributors may have less investment in ensuring that their work is completed in a timely manner, or is completed at all. This can be especially problematic if the work is important and others are relying on it. In a situation such as an event, it may be unavoidable to put responsibility on episodic participants.

Concern: 8.C Community's cost of supervision exceeds benefit of episodic contribution

Accepting work from new or episodic contributors is costly to the community. If the episodic contributor is experienced at contributing although not familiar with the community, the work will still need to be reviewed and possibly adapted before it can be used. If the episodic contributor is inexperienced, $\mathrm{s} /$ he may require assistance in working through the steps of making a contribution. It can be difficult for a community to absorb this cost when the long-term contributors could simply do the work themselves, more efficiently.

\section{D.3 Community Processes do not Support EV}

Concern: 9.C Community cannot retain episodic contributors for sporadic requirements

Some projects are not large enough to focus on many different tasks concurrently, and therefore have phases, for instance a documentation-improvement phase or a specificationdevelopment phase. In such an environment, the habitual contributor is the person who has a wide range of skills. People who are very skilled, but in one area of expertise, are difficult to retain as habitual contributors because of their narrow but deep skill-set. It can also be difficult to keep them as episodic contributors because their skills are required infrequently, at irregular intervals.

Concern: 10.C Community has difficulty identifying appropriate tasks for episodic contributors

Community managers find it difficult to identify and maintain a list of suitable tasks. It can be time-consuming to describe tasks so that they can be picked up by episodic contributors. 
Concern: 11.C Community lacks an episodic strategy The community must first decide that it is worth developing an episodic strategy, and once the decision is made, there is a lack of understanding about how to implement a strategy for engaging episodic contributors. Often it is difficult for habitual contributors to identify with the requirements of episodic participants.

Concern: 12.C Community insufficiently supports episodic contributors

Contributors who require sponsorship to participate in events or initiatives can be hesitant to do so when reimbursement is slow or disorganized. While someone who is deeply engaged in the community and can also bear the temporary loan of money may not be discouraged, contributors who have tighter finances and/or less emotional investment can be unable or unwilling to temporarily bear the cost of participation.

\section{D.4 Marginalization of Episodic Contributors}

Concern: 13.C Community restricts episodic contributors from leadership roles

In a situation where some participants are paid to contribute full-time, and other participants are either volunteers or paid but only able to spend part of their time on the project, there is a tendency for leadership roles and complicated tasks to be taken on by the people who have more time to contribute. This can lead to the leadership not being representative and the overall goal of the project being aligned with the requirements of some participants or their employers.

Concern: 14.C Community excludes episodic contributors from discussions and decisions

When discussions are held and decisions are made in an adhoc way, the perspective of people who are habitually engaged is favored because they have a greater probability of being present at the right moment. Episodic contributors, no matter how interested or committed, are excluded simply because they need to plan their availability.

Concern: 15.C Community gives episodic contributors reduced access to opportunities and rewards

Communities are often inclined to give awards and training opportunities based on previous participation. However, this model can fail to take into consideration the fact that a person may be contributing episodically due to other constraints, such as studies, and nonetheless feel extremely engaged. Contributors who feel that they are unappreciated because they aren't given opportunities to hone their skills, find employment, or access funding often become less enthusiastic, or drop out.

Concern: 16.C Community lacks appreciation for and recognition of episodic contributors

Other contributors may not be able to distinguish between returning episodic contributors and newcomers. A long-term returning episodic contributor can feel unappreciated when treated as a newcomer, regardless of whether it is done with welcoming intent or with an assumption that the episodic contributor's input can be dismissed due to lack of expertise about the project.

\section{APPENDIX E Practices}

This appendix lists all 65 practices which were identified in the study. Practices are shown by category.

\section{E.1 Community Governance}

\section{Practice G.1: Manage the delivery triangle}

Context: In any project, you can adjust resources, scope, or schedule (the delivery triangle). When a project relies on volunteers, resources (contributors) are limited and cannot be adjusted.

Concerns:

- 2.C Episodic contributor lacks awareness of opportunities to contribute

- 3.C Community lacks knowledge of availability of episodic contributors

Solution: Adjust scope (quality or features) or schedule when project releases cannot be completed on schedule at the desired level of quality with the expected features.

Related practices:

- G.2 Use longer delivery cycles is a more SPECIFIC practice.

- R.11 Announce milestones and celebrate meeting goals is a possible PRECEDING step.

Challenges: Changing the schedule can have a negative impact on stakeholders relying on a posted schedule, on episodic contributors expecting a set cycle, and on habitual contributors who feel pressured to complete the work; changing the scope is often a better choice.

Used by: $\mathrm{CM}_{3}, \mathrm{CM}_{18}, \mathrm{CM}_{19}$

\section{Practice G.2: Use longer delivery cycles}

Context: A community wants to ensure that all stakeholders have an opportunity to participate, but the community contains returning episodic contributors with time constraints. This often occurs in projects with many company-sponsored developers who work on various projects.

Concerns:

- 13.C Community restricts episodic contributors from leadership roles

Solution: Make release cycles longer in order to give episodic contributors the opportunity to contribute without intense time pressure. People who have multiple responsibilities will be able to participate in the project.

Related practices:

- G.1 Manage the delivery triangle is a more GENERAL practice.

- R.1 Publicize your release schedule is a COMPLEMENTARY practice.

- O.1 Learn about the experience, preferences, and time constraints of participants is a possible PRECEDING step.

Challenges: It is possible that extending the length of the cycle will simply reduce the priority of participation for some, and they will still not find the time to contribute. Increasing the delivery cycle can diminish enthusiasm among regular contributors.

Used by: $\mathrm{CM}_{17}, \mathrm{CM}_{18}$ 
Context: The community is engaged in creative or organizing work, such as planning an event, with a volunteer group containing episodic contributors. It is important to consider multiple opinions and exchange information effectively.

\section{Concerns:}

\section{- 6.C Episodic contributor quality of work is insufficient}

Solution: Host in-person meetings for creative or organizational work involving multiple volunteers. The frequency of meetings may vary by project: it could be yearly, quarterly, monthly, or even more frequent. With in-person meetings, information can be exchanged more efficiently. Synchronous communication allows for effective brainstorming and the development of ideas. Trust, friendship, and social capital are built in person. People are inspired and enthused toward collective action.

Challenges: It is only possible to do this when all participants are in close physical proximity. It can be difficult to arrange meeting space for a larger group. It may not be financially feasible to host in-person meetings; in such circumstances, online events can be an alternative. The optimal number of people for unstructured symmetric communication is low: with more than 20 people, presentations, rather than discussion, are likely to occur. This can be an ineffective method if people have erratic schedules. Documenting offline meetings in a textual form requires additional effort compared to textual forms of communication.

Used by: $\mathrm{CM}_{2}, \mathrm{CM}_{13}, \mathrm{CM}_{18}, \mathrm{CM}_{24}$

\section{Practice G.4: Make decisions in public}

Context: In a single-vendor community, decisions are made by the company, with business interests which may differ from the community interests. Volunteers feel excluded from decision-making.

\section{Concerns:}

- 14.C Community excludes episodic contributors from discussions and decisions

Solution: Ensure that decisions are made in a process which is both public and open to suggestions from contributors. Even if the decision is ultimately made by an authoritative body, the transparency of the process can make participants feel a part of it. Contributors are more efficient when they understand the steps which led to decisions.

\section{Related practices:}

- G.10 Make your leadership diverse is a COMPLEMENTARY practice.

- P.7 Hold open progress meetings is a COMPLEMENTARY practice.

- R.10 Promote episodic contributors is a COMPLEMENTARY practice.

Challenges: Documentation about the process must be maintained, as inaccurate information can cause more problems than lack of information.

Used by: $\mathrm{CM}_{2}, \mathrm{CM}_{3}, \mathrm{CM}_{4}, \mathrm{CM}_{5}, \mathrm{CM}_{6}, \mathrm{CM}_{13}, \mathrm{CM}_{14}, \mathrm{CM}_{16}$, $\mathrm{CM}_{18}, \mathrm{CM}_{24}$
Context: Episodic contributors do not necessarily know what level of quality is expected. The community is large and mature enough that lack of a common perspective causes problems, and contributors cannot be expected to tacitly acquire the knowledge.

\section{Concerns:}

- 4.C Episodic contributor lacks understanding of project vision

- 6.C Episodic contributor quality of work is insufficient

- 7.C Episodic contributor's timeliness and completion of work is poor

- 11.C Community lacks an episodic strategy

Solution: Create a community definition of quality so that episodic contributors will know what quality is expected. It will become significantly easier to follow many of the subsequent practices if quality is defined within the community.

Related practices:

- P.4 Document general working practices is a COMPLEMENTARY practice.

- G.6 Craft a community vision is a possible PRECEDING step.

- P.10 Keep communication channels active is a possible PRECEDING step.

- P.13 Have a social media team is a possible PRECEDING step.

- G.7 Define measuring and success is a possible SUCCEEDING step.

- P.5 Detail how to complete a task is a possible SUCCEEDING step.

- P.6 List current areas of activity is a possible SUCCEEDING step.

- W.5 Automate checking the quality of work is a possible SUCCEEDING step.

- W.6 Set expectations is a possible SUCCEEDING step.

- W.7 Reject contributions of insufficient quality is a possible SUCCEEDING step.

- W.8 Mentor to quality is a possible SUCCEEDING step.

Challenges: It can be difficult to retroactively apply a definition of quality to an existing project, when not all participants are in agreement.

Used by: $\mathrm{CM}_{5}, \mathrm{CM}_{13}, \mathrm{CM}_{14}, \mathrm{CM}_{18}, \mathrm{CM}_{24}$

Proposed by: $\mathrm{CM}_{16}, \mathrm{CM}_{19}$ 
Practice G.6: Craft a community vision

Context: A young community, or a community drawn together from multiple other communities, lacks a clear vision.

Concerns:

- 2.C Episodic contributor lacks awareness of opportunities to contribute

- 4.C Episodic contributor lacks understanding of project vision

- 11.C Community lacks an episodic strategy

Solution: Craft an inclusive community vision and a code of conduct. A clear vision statement helps people determine if they want to participate in the community. A vision which includes a Code of Conduct can help identify undesirable behaviors.

Related practices:

- G.10 Make your leadership diverse is a COMPLEMENTARY practice.

- P.11 Send ambassadors to small events is a COMPLEMENTARY practice.

- R.4 Instill a sense of community is a COMPLEMENTARY practice.

- G.5 Create a community definition of quality is a possible SUCCEEDING step.

- P.19 Educate sponsoring organizations is a possible SUCCEEDING step.

- W.1 Have a key contributor responsible is a possible SUCCEEDING step.

- W.11 Explain the context of the contribution is a possible SUCCEEDING step.

- W.12 Sever ties is a possible SUCCEEDING step.

- R.2 Encourage social connections is a possible SUCCEEDING step.

- R.11 Announce milestones and celebrate meeting goals is a possible SUCCEEDING step.

Challenges: It can take some time for a community vision to develop.

Used by: $\mathrm{CM}_{4}, \mathrm{CM}_{9}, \mathrm{CM}_{12}, \mathrm{CM}_{13}, \mathrm{CM}_{18}$

Proposed by: $\mathrm{CM}_{17}, \mathrm{CM}_{19}$

\section{Practice G.7: Define measuring and success}

Context: An initiative to increase engagement of episodic contributors is planned.

Concerns:

- 2.C Episodic contributor lacks awareness of opportunities to contribute

- 10.C Community has difficulty identifying appropriate tasks for episodic contributors

- 11.C Community lacks an episodic strategy

Solution: Define what successful engagement of episodic contributors looks like. Describe how you will measure the impact. Defining the desired outcome makes it easier to get buy-in from other participants, and will enable adjustments to the initiative.

Related practices:

- G.5 Create a community definition of quality is a possible PRECEDING step.

- P.3 Crowdsource identifying appropriate tasks is a possible PRECEDING step.

- P.10 Keep communication channels active is a possible SUCCEEDING step.

- R.11 Announce milestones and celebrate meeting goals is a possible SUCCEEDING step.

Challenges: The causal relationship between initiatives and outcomes will not always be clear.

Used by: $\mathrm{CM}_{5}, \mathrm{CM}_{13}, \mathrm{CM}_{14}$

Proposed by: $\mathrm{CM}_{17}, \mathrm{CM}_{18}$
Practice G.8: Centralize budgeting of sponsorships

Context: The community offers sponsorships and has a good understanding of the needs of participants. People are often unable to participate without sponsorship, and are unable to wait for reimbursement. Local organizers are also volunteers, with multiple responsibilities.

Concerns:

- 12.C Community insufficiently supports episodic contributors

Solution: Centralize the processing of sponsorships and reimbursements so that all claims will be processed in the same manner, and processing will be timely. The organization will not have to seek out volunteers who can be trusted to perform the task in time.

\section{Related practices:}

- G.9 Use an external provider for sponsorships is a possible ALTERNATIVE step.

Challenges: Conversion charges, fees, and delays may occur in transferring funds between countries. Centralized processing services may be unaware of local circumstances which may modify the required compensation. Extra capital is required to manage the sponsorship system.

Used by: $\mathrm{CM}_{8}, \mathrm{CM}_{13}$

Practice G.9: Use an external provider for sponsorships

Context: The community offers sponsorships and has a good understanding of the needs of participants. People are often unable to participate without sponsorship, and are unable to wait for reimbursement. Local organizers are also volunteers, with multiple responsibilities.

Concerns:

- 12.C Community insufficiently supports episodic contributors

Solution: Hire an external service provider to serve as an intermediary in providing sponsorships. Claims will not depend upon the availability of volunteers. Claims will be processed with an understanding of local requirements. There will not be delays due to difficulties related to transferring funds between countries. This can also benefit recruitment, as local intermediaries advertise that they are involved in the project.

Related practices:

- G.8 Centralize budgeting of sponsorships is a possible ALTERNATIVE step.

Challenges: Using an intermediary costs additional money. Identifying an appropriate intermediary in each area requires effort. Picking an external provider might cause friction between project members depending on the expectations of participants and the preferences of the project.

Used by: $\mathrm{CM}_{24}$

Proposed by: $\mathrm{CM}_{4}$ 


\section{E.2 Community Preparation}

Context: The project wants to encourage diversity and accessibility in the community.

Concerns:

- 5.C Episodic contributor and community have mismatched expectations

Solution: Try to have a diverse board or coordination group to review processes and ensure that they are welcoming and accessible. Diversity and accessibility in the community can be increased when leaders understand the issues from personal experience.

\section{Related practices:}

- G.4 Make decisions in public is a COMPLEMENTARY practice.

- G.6 Craft a community vision is a COMPLEMENTARY practice.

Used by: $\mathrm{CM}_{6}, \mathrm{CM}_{24}$

\section{Practice G.11: Seek sponsorship}

Context: The community relies on regular meetings and is not affiliated with any companies.

\section{Concerns:}

- 9.C Community cannot retain episodic contributors for sporadic requirements

Solution: Look for a stable sponsor to ensure continuity of events. Funding allows organizations to offer swag, snacks, and a location for meetings. Having an assured venue allows episodic participants to return easily. People are more inclined to contribute to mature communities because it improves their employment prospects.

\section{Related practices:}

- P.7 Hold open progress meetings is a possible SUCCEEDING step.

Used by: $\mathrm{CM}_{24}$
Practice P.1: Identify appropriate tasks

Context: There are components of the project which could be divided into small tasks.

Concerns:

- 2.C Episodic contributor lacks awareness of opportunities to contribute

- 5.C Episodic contributor and community have mismatched expectations

- 10.C Community has difficulty identifying appropriate tasks for episodic contributors

- 11.C Community lacks an episodic strategy

Solution: Episodic participants can more easily join if tasks are available. Identify the types of tasks which are suited for episodic contributors. These will probably be short-term and require little knowledge of the project.

Related practices:

- P.2 Define one-off tasks is a more SPECIFIC practice.

- P.3 Crowdsource identifying appropriate tasks is a more SPECIFIC practice.

- O.1 Learn about the experience, preferences, and time constraints of participants is a COMPLEMENTARY practice.

- W.1 Have a key contributor responsible is a COMPLEMENTARY practice.

- P.6 List current areas of activity is a possible PRECEDING step.

- P.3Crowdsource identifying appropriate tasks is a possible SUCCEEDING step.

- P.10 Keep communication channels active is a possible SUCCEEDING step.

- P.13 Have a social media team is a possible SUCCEEDING step.

- O.4 Give a choice of tasks is a possible SUCCEEDING step.

- R.12 Listen to suggestions is a possible SUCCEEDING step.

Challenges: It requires time and effort to identify appropriate tasks. People may only be able to identify tasks within their own area of expertise.

Used by: $\mathrm{CM}_{3}, \mathrm{CM}_{5}, \mathrm{CM}_{6}, \mathrm{CM}_{7}, \mathrm{CM}_{10}, \mathrm{CM}_{13}, \mathrm{CM}_{14}, \mathrm{CM}_{18}$, $\mathrm{CM}_{19}$

Proposed by: $\mathrm{CM}_{17}$
Practice P.2: Define one-off tasks

Context: People have shown interest in the initiative, but appear unwilling to commit to ongoing participation. Work can be divided into discrete tasks.

Concerns:

- 7.C Episodic contributor's timeliness and completion of work is poor

Solution: Create stand-alone, one-off tasks. You will discover quickly if participants do not complete their tasks. If people can participate without long-term obligation, more people might try it. If people participate successfully, they may choose to participate again

Related practices:

- P.1 Identify appropriate tasks is a more GENERAL practice.

- P.5 Detail how to complete a task is a more GENERAL practice.

- O.1 Learn about the experience, preferences, and time constraints of participants is a COMPLEMENTARY practice.

- O.3 Guide people to junior jobs is a possible SUCCEEDING step.

Challenges: More time will be spent managing to the initiative

Used by: $\mathrm{CM}_{5}, \mathrm{CM}_{14}, \mathrm{CM}_{19}, \mathrm{CM}_{24}$ 
Practice P.3: Crowdsource identifying appropriate tasks

Context: There are components of the project which could be divided into small tasks, but identifying and preparing the tasks would be time-consuming.

\section{Concerns:}

- 2.C Episodic contributor lacks awareness of opportunities to contribute

- 10.C Community has difficulty identifying appropriate tasks for episodic contributors

Solution: A group of people can more effectively identify outstanding issues than a single person. Engage experienced contributors in a short-term initiative to identify outstanding issues which could be handled by episodic contributors. Encourage them to continue to identify new tasks, once the backlog has been addressed.

Related practices:

- P.1 Identify appropriate tasks is a more GENERAL practice.

- P.6 List current areas of activity is a more GENERAL practice.

- P.1 Identify appropriate tasks is a possible PRECEDING step.

- G.7 Define measuring and success is a possible SUCCEEDING step.

Challenges: Maintaining the list of appropriate tasks requires convincing contributors of the benefits of engaging episodic participants.

Used by: $\mathrm{CM}_{5}, \mathrm{CM}_{18}$

\section{Practice P.4: Document general working practices}

Context: Repeated processes are not well documented. Newcomers and episodic participants cannot be expected to be familiar with implicit processes.

Concerns:

- 1.C Episodic contributor lacks knowledge of developments during absences

- 2.C Episodic contributor lacks awareness of opportunities to contribute

- 5.C Episodic contributor and community have mismatched expectations

- 6.C Episodic contributor quality of work is insufficient

- 10.C Community has difficulty identifying appropriate tasks for episodic contributors

- 11.C Community lacks an episodic strategy

Solution: Document the community's working practices, placing particular emphasis on those areas which are most likely to be relevant to new and episodic contributors, and where contributions will be most appreciated. Episodic contributors and newcomers can more easily become familiar with the community and consistency of the contribution experience is increased.

Related practices:

- W.13 Automate process assistance is a more SPECIFIC practice.

- G.5 Create a community definition of quality is a COMPLEMENTARY practice.

- P.5 Detail how to complete a task is a COMPLEMENTARY practice.

- P.18 Write modular software is a COMPLEMENTARY practice.

- P.20 Offer a consistent development environment is a COMPLEMENTARY practice.

- R.12 Listen to suggestions is a COMPLEMENTARY practice.

- P.10 Keep communication channels active is a possible PRECEDING step.

- P.13 Have a social media team is a possible PRECEDING step.

- P.5 Detail how to complete a task is a possible SUCCEEDING step.

- W.9 Require documentation as part of the submission is a possible SUCCEEDING step.

Challenges: Processes which are written down do not always match actual practice, and must be revised to be kept up-todate. It can be time-consuming to document practices.

Used by: $\mathrm{CM}_{2}, \mathrm{CM}_{3}, \mathrm{CM}_{4}, \mathrm{CM}_{5}, \mathrm{CM}_{7}, \mathrm{CM}_{10}, \mathrm{CM}_{13}, \mathrm{CM}_{14}$, $\mathrm{CM}_{16}, \mathrm{CM}_{18}, \mathrm{CM}_{19}, \mathrm{CM}_{24}$

Proposed by: $\mathrm{CM}_{1}, \mathrm{CM}_{6}, \mathrm{CM}_{11}$ 
Context: Tasks are repeatable and well-understood, or have repeatable and well-understood components. Episodic contributors are not equipped to understand the skills required to complete a task, the length of time a task will take, or the steps to completing a task.

\section{Concerns:}

- 2.C Episodic contributor lacks awareness of opportunities to contribute

- 4.C Episodic contributor lacks understanding of project vision

- 5.C Episodic contributor and community have mismatched expectations

- 6.C Episodic contributor quality of work is insufficient

- 7.C Episodic contributor's timeliness and completion of work is poor

- 10.C Community has difficulty identifying appropriate tasks for episodic contributors

- 11.C Community lacks an episodic strategy

Solution: Do not just summarize tasks, but detail the steps that need to be taken, and consider providing a time estimate for the task. If a task is repeatable, documenting it helps ensure consistent results. Participants who have a good experience and realistic expectations are more likely to return.

Related practices:

- P.2 Define one-off tasks is a more SPECIFIC practice.

- P.4 Document general working practices is a COMPLEMENTARY practice.

- P.6 List current areas of activity is a COMPLEMENTARY practice.

- G.5 Create a community definition of quality is a possible PRECEDING step.

- P.4 Document general working practices is a possible PRECEDING step.

Challenges: It can take significant time to describe tasks well, and people may find it easier to do the tasks themselves than to explain how to do tasks. It is very difficult to provide an accurate time assessment, especially when an experienced person is evaluating the time a non-experienced contributor needs.

Used by: $\mathrm{CM}_{2}, \mathrm{CM}_{3}, \mathrm{CM}_{4}, \mathrm{CM}_{7}, \mathrm{CM}_{10}, \mathrm{CM}_{13}, \mathrm{CM}_{14}, \mathrm{CM}_{18}$, $\mathrm{CM}_{24}$

Proposed by: $\mathrm{CM}_{6}, \mathrm{CM}_{16}, \mathrm{CM}_{17}, \mathrm{CM}_{19}$
Context: There are areas where episodic contributors could participate, and the work can be described as a series of discrete tasks. Episodic contributors do not know what tasks may be suitable and available. Often, the community is larger.

Concerns:

- 2.C Episodic contributor lacks awareness of opportunities to contribute

- 4.C Episodic contributor lacks understanding of project vision

- 10.C Community has difficulty identifying appropriate tasks for episodic contributors

- 11.C Community lacks an episodic strategy

Solution: Prioritize tasks and tag them as entry level where appropriate. Group similar tasks together. Episodic contributors can more readily find appropriate tasks.

\section{Related practices:}

- P.3 Crowdsource identifying appropriate tasks is a more SPECIFIC practice.

- P.7 Hold open progress meetings is a possible ALTERNATIVE step.

- P.8 Create working groups with a narrow focus is a possible ALTERNATIVE step.

- P.5 Detail how to complete a task is a COMPLEMENTARY practice.

- P.14 Set expiration dates is a COMPLEMENTARY practice.

- G.5 Create a community definition of quality is a possible PRECEDING step.

- R.12 Listen to suggestions is a possible PRECEDING step.

- P.1 Identify appropriate tasks is a possible SUCCEEDING step.

- P.13 Have a social media team is a possible SUCCEEDING step.

- O.5 Manage task assignments with an application is a possible SUCCEEDING step.

Challenges: It can be time-consuming to maintain an up-todate task list.

Used by: $\mathrm{CM}_{5}, \mathrm{CM}_{13}, \mathrm{CM}_{16}, \mathrm{CM}_{18}, \mathrm{CM}_{24}$

Proposed by: $\mathrm{CM}_{2}, \mathrm{CM}_{3}, \mathrm{CM}_{4}, \mathrm{CM}_{14}, \mathrm{CM}_{19}$ 
Practice P.7: Hold open progress meetings

Context: The community is small and there are areas where episodic contributors could participate, but episodic contributors do not know the current status of development.

\section{Concerns:}

- 1.C Episodic contributor lacks knowledge of developments during absences

- 2.C Episodic contributor lacks awareness of opportunities to contribute

- 14.C Community excludes episodic contributors from discussions and decisions

Solution: Hold regular open meetings where previous work is summarized, and new tasks are assigned. People can attend meetings when they want to get caught up quickly on the current status, and do not need to participate every time.

Related practices:

- P.6 List current areas of activity is a possible ALTERNATIVE step.

- P.9 Create written records of activity is a possible ALTERNATIVE step.

- O.5 Manage task assignments with an application is a possible ALTERNATIVE step.

- G.4 Make decisions in public is a COMPLEMENTARY practice.

- G.11 Seek sponsorship is a possible PRECEDING step.

Challenges: Once a community becomes larger, it is not possible to efficiently cover all topics in one meeting. Arranging regular meetings can be difficult, as people may have other priorities.

Used by: $\mathrm{CM}_{3}, \mathrm{CM}_{4}, \mathrm{CM}_{13}, \mathrm{CM}_{16}, \mathrm{CM}_{18}$

\section{Practice P.9: Create written records of activity}

Context: It is a large community, with many activities taking place at a rapid rate. Episodic contributors do not know the current status of development, but there are areas where episodic contributors could participate.

\section{Concerns:}

- 1.C Episodic contributor lacks knowledge of developments during absences

- 2.C Episodic contributor lacks awareness of opportunities to contribute

- 14.C Community excludes episodic contributors from discussions and decisions

Solution: Maintain a summary, for instance in the form of a newsletter, which describes the key discussions and resolutions which took place during a given period. Alternately, rely on written communications (mailing lists, chats) or provide meeting minutes. Episodic contributors will find it easier to return to the project, and summaries can serve as a reference for the entire community.

Related practices:

- $\quad$.7 Hold open progress meetings is a possible ALTERNATIVE step.

Challenges: It is time-consuming to create summaries.

Used by: $\mathrm{CM}_{15}, \mathrm{CM}_{24}$

Practice P.8: Create working groups with a narrow focus

Context: The project is too complex for participants to easily comprehend it in its entirety. It is not possible to readily identify stand-alone tasks in the project.

\section{Concerns:}

- 2.C Episodic contributor lacks awareness of opportunities to contribute

Solution: Create specialized working groups that people can identify with. With a narrow focus and defined outcomes, episodic contributors will be able to find tasks more readily.

\section{Related practices:}

- P.6 List current areas of activity is a possible ALTERNATIVE step.

- $\quad$ P.18 Write modular software is a possible ALTERNATIVE step.

- P.18 Write modular software is a COMPLEMENTARY practice.

- P.18 Write modular software is a possible PRECEDING step.

- O.1 Learn about the experience, preferences, and time constraints of participants is a possible PRECEDING step.

Challenges: Contributions within the working groups will need to be reported back to the larger group.

Used by: $\mathrm{CM}_{2}, \mathrm{CM}_{3}, \mathrm{CM}_{4}, \mathrm{CM}_{5}, \mathrm{CM}_{6}, \mathrm{CM}_{16}$ 
Context: People seeking to participate require interaction to ask questions or make their contributions.

Concerns:

- 2.C Episodic contributor lacks awareness of opportunities to contribute

- 4.C Episodic contributor lacks understanding of project vision

- 5.C Episodic contributor and community have mismatched expectations

- 10.C Community has difficulty identifying appropriate tasks for episodic contributors

- 11.C Community lacks an episodic strategy

Solution: Ensure that communication channels both online and offline are monitored, and that queries are directed to appropriate people. Make sure that people receive responses. Active communication channels allow people to be aware of opportunities to participate.

\section{Related practices:}

- P.11 Send ambassadors to small events is a more SPECIFIC practice.

- P.12 Respond to all submissions is a more SPECIFIC practice.

- P.13 Have a social media team is a COMPLEMENTARY practice.

- G.7 Define measuring and success is a possible PRECEDING step.

- P.1 Identify appropriate tasks is a possible PRECEDING step.

- W.1 Have a key contributor responsible is a possible PRECEDING step.

- G.5 Create a community definition of quality is a possible SUCCEEDING step.

- P.4 Document general working practices is a possible SUCCEEDING step.

- R.7 Recognize everyone is a possible SUCCEEDING step.

Challenges: If there are too many communication channels a message might be sent to the wrong channel or ignored. If multiple people are managing the communication channels, care should be taken that different channels don't send contradictory messages. Someone must be responsible for maintaining each communication channel, and following up on redirected queries. If there are already few volunteers, this may require too much time and effort.

Used by: $\mathrm{CM}_{3}, \mathrm{CM}_{4}, \mathrm{CM}_{5}, \mathrm{CM}_{7}, \mathrm{CM}_{13}, \mathrm{CM}_{14}, \mathrm{CM}_{18}, \mathrm{CM}_{19}$ $\mathrm{CM}_{24}$

Proposed by: $\mathrm{CM}_{6}, \mathrm{CM}_{8}, \mathrm{CM}_{17}$
Context: This practice can be applied when the community wishes to become better known in the region.

Concerns:

- 2.C Episodic contributor lacks awareness of opportunities to contribute

Solution: Send ambassadors to attend smaller events, to enable personal interactions with potential participants. Sending episodic contributors to small events with a sponsorship can also be a form of reward.

\section{Related practices:}

- P.10 Keep communication channels active is a more GENERAL practice.

- R.2 Encourage social connections is a more GENERAL practice.

- R.6 Reward participation is a more GENERAL practice.

- G.6 Craft a community vision is a COMPLEMENTARY practice.

- P.17 Provide templates for presentations is a COMPLEMENTARY practice.

- W.1 Have a key contributor responsible is a possible SUCCEEDING step.

- R.2 Encourage social connections is a possible SUCCEEDING step.

Challenges: It is important to pick relevant events. Large projects might be expected to provide swag for attendees, which could increase costs.

Used by: $\mathrm{CM}_{2}, \mathrm{CM}_{5}, \mathrm{CM}_{9}, \mathrm{CM}_{13}, \mathrm{CM}_{18}, \mathrm{CM}_{19}, \mathrm{CM}_{24}$

Proposed by: $\mathrm{CM}_{8}$

\section{Practice P.12: Respond to all submissions}

Context: One-off contributions are common, but contributions do not always contain sufficient information to allow them to be incorporated or maintained without involvement from their authors.

Concerns:

- 7.C Episodic contributor's timeliness and completion of work is poor

Solution: Respond to every submission in a timely manner. This makes it more likely that the contributor is still available, while other contributors make sure they understand the submission. This way, the people who could end up maintaining the submission will be able to do so.

Related practices:

- P.10 Keep communication channels active is a more GENERAL practice.

- W.1 Have a key contributor responsible is a more GENERAL practice.

- O.6 Explain the need for maintenance is a COMPLEMENTARY practice.

- W.9 Require documentation as part of the submission is a COMPLEMENTARY practice.

Used by: $\mathrm{CM}_{3}, \mathrm{CM}_{4}, \mathrm{CM}_{10}, \mathrm{CM}_{13}, \mathrm{CM}_{24}$ 


\section{Practice P.13: Have a social media team}

Context: Core developers often do not enjoy engaging in social media. The community wants to maintain active communication channels.

\section{Concerns:}

- 2.C Episodic contributor lacks awareness of opportunities to contribute

- 11.C Community lacks an episodic strategy

Solution: Recruit people who enjoy social media specifically for the task of communicating with potential and episodic contributors. If the work is done by people who enjoy it, it will probably be done more effectively. The team can include episodic contributors.

\section{Related practices:}

- P.10 Keep communication channels active is a COMPLEMENTARY practice.

- P.1 Identify appropriate tasks is a possible PRECEDING step.

- P.6 List current areas of activity is a possible PRECEDING step.

- W.1 Have a key contributor responsible is a possible PRECEDING step.

- G.5 Create a community definition of quality is a possible SUCCEEDING step.

- P.4 Document general working practices is a possible SUCCEEDING step.

- R.11 Announce milestones and celebrate meeting goals is a possible SUCCEEDING step.

Challenges: If the social media team is supplying information on areas outside of their expertise, they may still need to consult core contributors. If multiple people are managing the communication channels, care should be taken that different channels don't send contradictory messages.

Used by: $\mathrm{CM}_{3}, \mathrm{CM}_{5}, \mathrm{CM}_{13}, \mathrm{CM}_{18}, \mathrm{CM}_{24}$

Proposed by: $\mathrm{CM}_{6}, \mathrm{CM}_{11}$

\section{Practice P.14: Set expiration dates}

Context: An initiative which is expected to draw in new episodic contributors is planned.

Concerns:

- 7.C Episodic contributor's timeliness and completion of work is poor

Solution: Set distinct deadlines for initiatives. Setting an end date for the initiative gives structure to the process and discourages procrastination.

Related practices:

- P.15 Create continual points of entry is a possible ALTERNATIVE step.

- P.6 List current areas of activity is a COMPLEMENTARY practice.

- R.14 Rotate focus areas on schedule is a COMPLEMENTARY practice.

Challenges: People who cannot participate during the time the initiative is scheduled cannot participate at all.

Used by: $\mathrm{CM}_{13}, \mathrm{CM}_{14}, \mathrm{CM}_{18}, \mathrm{CM}_{19}$

\section{Practice P.15: Create continual points of entry}

Context: The community wants to increase episodic participation.

Concerns:

- 11.C Community lacks an episodic strategy

Solution: Create ongoing ways for people to join the project and contribute, rather than providing only specific times or times in the process when people can join. This allows people to participate whenever they have the opportunity.

Related practices:

- P.14 Set expiration dates is a possible ALTERNATIVE step.

Challenges: This approach will not discourage procrastination

Used by: $\mathrm{CM}_{13}, \mathrm{CM}_{19}$

Proposed by: $\mathrm{CM}_{17}$

\section{Practice P.16: Share success stories}

Context: The community wants to communicate to its members and potential members the positive effects of participation.

Concerns:

- 4.C Episodic contributor lacks understanding of project vision

Solution: Share stories about outstanding or long-serving community members and the challenges they faced and benefits they received. Including stories about episodic contributors may make participation seem less overwhelming.

Related practices:

- W.10 Encourage learners to mentor is a COMPLEMENTARY practice.

Used by: $\mathrm{CM}_{13}, \mathrm{CM}_{14}, \mathrm{CM}_{19}, \mathrm{CM}_{24}$
Practice P.17: Provide templates for presentations

Context: Your community wants to encourage more of your contributors to speak at events about your project.

Concerns:

- 2.C Episodic contributor lacks awareness of opportunities to contribute

Solution: Create one or more standard slide decks which your contributors can use with or without modification. Contributors may be more likely to present if they do not have to create the material themselves.

Related practices:

- P.11 Send ambassadors to small events is a COMPLEMENTARY practice.

Used by: $\mathrm{CM}_{10}, \mathrm{CM}_{18}$ 
Context: This practice concerns software development only.

\section{Concerns:}

- 10.C Community has difficulty identifying appropriate tasks for episodic contributors

Solution: Ensure that software is modular. Episodic contributors can work on smaller areas without understanding the bigger picture.

\section{Related practices:}

- P.8 Create working groups with a narrow focus is a possible ALTERNATIVE step.

- P.4 Document general working practices is a COMPLEMENTARY practice.

- P.8 Create working groups with a narrow focus is a COMPLEMENTARY practice.

- P.8 Create working groups with a narrow focus is a possible SUCCEEDING step.

Challenges: If the software has not been designed to be modular, significant effort will be required to revise it.

Used by: $\mathrm{CM}_{5}, \mathrm{CM}_{6}, \mathrm{CM}_{14}, \mathrm{CM}_{16}, \mathrm{CM}_{18}$

Practice P.19: Educate sponsoring organizations

Context: In a community where the majority of participants are paid employees, yet contributions are often inappropriate or of insufficient quality.

\section{Concerns:}

- 4.C Episodic contributor lacks understanding of project vision

- 11.C Community lacks an episodic strategy

Solution: Educate sponsoring organizations about participation in open source projects, including topics such as the necessity of maintenance and the open model of production. Problematic contributions which stem from inadequate knowledge should diminish.

\section{Related practices:}

- W.11 Explain the context of the contribution is a possible ALTERNATIVE step.

- G.6 Craft a community vision is a possible PRECEDING step.

Challenges: It can be difficult to educate a company, if the problem does not lie with individual contributors.

Used by: $\mathrm{CM}_{16}, \mathrm{CM}_{18}, \mathrm{CM}_{24}$

Proposed by: $\mathrm{CM}_{17}$
Context: Episodic and new contributors are unlikely to be familiar with any project-specific development processes, and may lack familiarity with some of the tools used, leading to pull-requests which do not conform to expectations. This arises most often with software development, but may also apply to other areas where tooling is used, such as translation.

Concerns:

- 2.C Episodic contributor lacks awareness of opportunities to contribute

- 6.C Episodic contributor quality of work is insufficient

Solution: Document the workflow, architecture of the module, and use a container to build your project in order to allow people to easily build a local system. Decide upon one recommended way to set up a development environment and focus on this in the documentation. More complicated needs can be addressed elsewhere.

Related practices:

- W.8 Mentor to quality is a possible SUCCEEDING step.

Used by: $\mathrm{CM}_{14}$

Proposed by: $\mathrm{CM}_{4}, \mathrm{CM}_{11}$

\section{E.3 Onboarding Contributors}

Practice 0.1: Learn about the experience, preferences, and time constraints of participants

Context: New and episodic contributors have different intentions and expectations about their participation. Mentors are frustrated by investing time and energy in people who don't intend to become habitual contributors.

Concerns:

- 5.C Episodic contributor and community have mismatched expectations

- 10.C Community has difficulty identifying appropriate tasks for episodic contributors

- 11.C Community lacks an episodic strategy

Solution: Most people have a good understanding of their own situation and can communicate their interests and skills. Frustration among mentors is reduced when the intentions of participants are known up-front. Ask new and infrequent contributors about their expectations, availability, preferences and experience. Do not reproach them for their answers. Guide them toward identifying suitable work.

Related practices:

- 0.2 Screen potential contributors is a more SPECIFIC practice.

- O.3 Guide people to junior jobs is a possible ALTERNATIVE step.

- G.2 Use longer delivery cycles is a COMPLEMENTARY practice.

- P.1 Identify appropriate tasks is a COMPLEMENTARY practice.

- P.2 Define one-off tasks is a possible SUCCEEDING step.

- P.8 Create working groups with a narrow focus is a possible SUCCEEDING step.

- O.4 Give a choice of tasks is a possible SUCCEEDING step.

- W.10 Encourage learners to mentor is a possible SUCCEEDING step.

- R.14 Rotate focus areas on schedule is a possible SUCCEEDING step.

Challenges: Engaging people early on to determine their intentions takes time.

Used by: $\mathrm{CM}_{3}, \mathrm{CM}_{6}, \mathrm{CM}_{13}$

Proposed by: $\mathrm{CM}_{8}, \mathrm{CM}_{16}, \mathrm{CM}_{17}, \mathrm{CM}_{19}$ 
Context: In order for a contributor to properly perform a role a certain minimum commitment is required. The project has repeated problems with people insufficiently committing to roles.

\section{Concerns:}

- 3.C Community lacks knowledge of availability of episodic contributors

- 4.C Episodic contributor lacks understanding of project vision

- 5.C Episodic contributor and community have mismatched expectations

- 10.C Community has difficulty identifying appropriate tasks for episodic contributors

Solution: Screen potential contributors to determine if they are a good match for the role. This may include having availability at the appropriate time, or being able to commit to a certain amount of time. It is less likely that the commitment will not be met.

Related practices:

- O.1 Learn about the experience, preferences, and time constraints of participants is a more GENERAL practice.

Challenges: Some people will be prevented from pursuing the role, but if there are other forms of contribution it does not prevent them from participating altogether. Assessing potential contributors requires effort.

Used by: $\mathrm{CM}_{3}, \mathrm{CM}_{8}, \mathrm{CM}_{10}, \mathrm{CM}_{13}, \mathrm{CM}_{14}$

\section{Practice O.3: Guide people to junior jobs}

Context: People have difficulty articulating their preferences and experience when it comes to choosing a task.

Concerns:

- 2.C Episodic contributor lacks awareness of opportunities to contribute

Solution: Guide people to junior jobs when they do not know where to start.

\section{Related practices:}

- O.1 Learn about the experience, preferences, and time constraints of participants is a possible ALTERNATIVE step.

- P.2 Define one-off tasks is a possible PRECEDING step.

Used by: $\mathrm{CM}_{10}, \mathrm{CM}_{13}, \mathrm{CM}_{14}, \mathrm{CM}_{20}$

\section{Practice O.4: Give a choice of tasks}

Context: Tasks are largely assigned to participants in an initiative, rather than being self-selected.

Concerns:

- 10.C Community has difficulty identifying appropriate tasks for episodic contributors

Solution: Give participants a choice of the task, from a small number offered to them. People are able to select a task which they have the most affinity for.

\section{Related practices:}

- W.3 Give permission to quit a task is a COMPLEMENTARY practice.

- P.1 Identify appropriate tasks is a possible PRECEDING step.

- O.1 Learn about the experience, preferences, and time constraints of participants is a possible PRECEDING step.

Challenges: Some tasks will not be selected but will still need to be completed.

Used by: $\mathrm{CM}_{10}, \mathrm{CM}_{13}, \mathrm{CM}_{14}, \mathrm{CM}_{19}$
Context: The group is large enough, or spread out enough, that task assignment cannot be discussed between all participants, but tasks need to be assigned to specific people.

Concerns:

- 1.C Episodic contributor lacks knowledge of developments during absences

- 2.C Episodic contributor lacks awareness of opportunities to contribute

- 6.C Episodic contributor quality of work is insufficient

- 11.C Community lacks an episodic strategy

Solution: Use an application, such as a wiki or bug tracking system, to handle the assignment process. This prevents work duplication and allows self-assignment.

\section{Related practices:}

- P.7 Hold open progress meetings is a possible ALTERNATIVE step.

- P.6 List current areas of activity is a possible PRECEDING step.

Challenges: If you do not already have a system for allocating tasks (especially non-coding tasks), implementation may require some work. Current participants may not be willing to switch to a new way of working.

Used by: $\mathrm{CM}_{3}, \mathrm{CM}_{6}, \mathrm{CM}_{13}$

Proposed by: $\mathrm{CM}_{22}, \mathrm{CM}_{24}$
Practice O.6: Explain the need for maintenance

Context: Submissions usually require maintenance for a period of time after they are incorporated, but contributors prefer drive-by contributions. This approach is most effective where the contributors have an ongoing link with the community which discourages them from dumping their contributions, such as being paid by a company to make occasional contributions.

Concerns:

- 4.C Episodic contributor lacks understanding of project vision

- 7.C Episodic contributor's timeliness and completion of work is poor

Solution: Educate contributors about what happens to a contribution after it is included in the project. Explain the benefits to the project if they remain available to maintain their contribution. If people understand the effect of not remaining available to maintain a contribution, they may consider remaining.

Related practices:

- P.12 Respond to all submissions is a COMPLEMENTARY practice.

- W.9 Require documentation as part of the submission is a COMPLEMENTARY practice.

- W.11 Explain the context of the contribution is a COMPLEMENTARY practice.

Challenges: People may not be willing to remain, and cannot be made to remain.

Used by: $\mathrm{CM}_{17}, \mathrm{CM}_{18}, \mathrm{CM}_{20}$

Proposed by: $\mathrm{CM}_{10}$ 


\section{Practice 0.7: Offer guided introductory events}

Context: People may be lack the confidence to make code contributions on their own, but are nonetheless interested in participating.

\section{Concerns:}

- 2.C Episodic contributor lacks awareness of opportunities to contribute

- 5.C Episodic contributor and community have mismatched expectations

Solution: At events, offer walk-through tutorials on getting started as a contributor, culminating in a hackathon working on a specific beginner problem. Guided introductory events often attract one-off contributors, but can also encourage some returning episodic contributors.

Used by: $\mathrm{CM}_{19}$

\section{Practice W.2: Issue reminders}

Context: This practice applies to a time-sensitive project, such as event organization.

Concerns:

- 3.C Community lacks knowledge of availability of episodic contributors

- 7.C Episodic contributor's timeliness and completion of work is poor

Solution: Send a reminder as the deadline approaches. Be persistent in following up on deliverables. Reminding people increases the chance of the task being completed.

Related practices:

- W.1 Have a key contributor responsible is a more GENERAL practice.

Challenges: It can be time-consuming to keep track of participants and the status of their tasks. Reminding people will not always result in the task being done.

Used by: $\mathrm{CM}_{8}, \mathrm{CM}_{13}, \mathrm{CM}_{14}, \mathrm{CM}_{18}, \mathrm{CM}_{19}, \mathrm{CM}_{24}$

\section{E.4 Working with Contributors}

\section{Practice W.1: Have a key contributor responsible}

Context: This practice is relevant when managing ongoing or temporary projects where episodic contributors are participating.

Concerns:

- 2.C Episodic contributor lacks awareness of opportunities to contribute

- 6.C Episodic contributor quality of work is insufficient

- 7.C Episodic contributor's timeliness and completion of work is poor

- 11.C Community lacks an episodic strategy

- 16.C Community lacks appreciation for and recognition of episodic contributors

Solution: For every important project, make sure that one key contributor is responsible for managing it and responding to inquiries. There is less chance that important tasks will slip through the cracks.

\section{Related practices:}

- P.12 Respond to all submissions is a more SPECIFIC practice.

- W.2 Issue reminders is a more SPECIFIC practice.

- W.3 Give permission to quit a task is a more SPECIFIC practice.

- P.1 Identify appropriate tasks is a COMPLEMENTARY practice.

- W.4 Encourage people to quit is a COMPLEMENTARY practice.

- W.10 Encourage learners to mentor is a COMPLEMENTARY practice.

- G.6 Craft a community vision is a possible PRECEDING step.

- P.11 Send ambassadors to small events is a possible PRECEDING step.

- P.10 Keep communication channels active is a possible SUCCEEDING step.

- P.13 Have a social media team is a possible SUCCEEDING step.

Challenges: If a single person is responsible, it is a potential point of failure if they are unavailable when they are needed

Used by: $\mathrm{CM}_{2}, \mathrm{CM}_{3}, \mathrm{CM}_{5}, \mathrm{CM}_{9}, \mathrm{CM}_{13}, \mathrm{CM}_{14}, \mathrm{CM}_{24}$

Proposed by: $\mathrm{CM}_{6}$

\section{Practice W.3: Give permission to quit a task}

Context: This practice concerns supervising episodic contributors for an ongoing initiative.

\section{Concerns:}

- 3.C Community lacks knowledge of availability of episodic contributors

- 7.C Episodic contributor's timeliness and completion of work is poor

Solution: Give people permission to skip on period or task, without recrimination. People may be more inclined to continue, if they have an out from a stressful situation. Planning can also be improved if people feel they can honestly express their true availability.

\section{Related practices:}

- W.1 Have a key contributor responsible is a more GENERAL practice.

- W.4 Encourage people to quit is a possible ALTERNATIVE step.

- O.4 Give a choice of tasks is a COMPLEMENTARY practice.

- W.6 Set expectations is a COMPLEMENTARY practice.

Challenges: Some people will feel guilty anyway, and drop out.

Used by: $\mathrm{CM}_{6}, \mathrm{CM}_{19}, \mathrm{CM}_{24}$ 


\section{Practice W.4: Encourage people to quit}

Context: A contributor accepts responsibilities which others depend upon. The contributor's participation subsequently becomes episodic and non-responsive.

Concerns:

- 3.C Community lacks knowledge of availability of episodic contributors

- 7.C Episodic contributor's timeliness and completion of work is poor

Solution: People who no longer wish to fulfill a role or complete tasks should be encouraged to step down. This allows tasks to be reassigned appropriately, and for the initiative to be organized according to actual availability.

\section{Related practices:}

- W.1 Have a key contributor responsible is a more GENERAL practice.

- W.3 Give permission to quit a task is a possible ALTERNATIVE step.

- W.9 Require documentation as part of the submission is a possible PRECEDING step.

Used by: $\mathrm{CM}_{16}, \mathrm{CM}_{19}$

Proposed by: $\mathrm{CM}_{8}$

\section{Practice W.5: Automate checking the quality of work}

Context: This practice is specific to software development. It is necessary to check the quality of code submissions, and the work is too time-consuming to effectively do it manually. Usually this problem occurs in larger communities.

Concerns:

- 4.C Episodic contributor lacks understanding of project vision

- 6.C Episodic contributor quality of work is insufficient

- 8.C Community's cost of supervision exceeds benefit of episodic contribution

- 10.C Community has difficulty identifying appropriate tasks for episodic contributors

- 11.C Community lacks an episodic strategy

Solution: Utilize advances in continuous integration/continuous delivery to automate routine evaluation. Reviewers are free to focus on strategic reviews. A minimal level of quality will always be maintained, and participants may be less likely to take offense when informed of problems by automated processes.

\section{Related practices:}

-W.6 Set expectations is a COMPLEMENTARY practice.

- W.7 Reject contributions of insufficient quality is a COMPLEMENTARY practice.

- G.5 Create a community definition of quality is a possible PRECEDING step.

Challenges: There is a lack of guidance on how to easily set up and apply these processes to open source projects.

Used by: $\mathrm{CM}_{2}, \mathrm{CM}_{5}, \mathrm{CM}_{7}, \mathrm{CM}_{16}, \mathrm{CM}_{18}$

Proposed by: $\mathrm{CM}_{4}, \mathrm{CM}_{19}$
Practice W.6: Set expectations

Context: People frequently are lax in completing tasks, and in communicating their progress.

Concerns:

- 7.C Episodic contributor's timeliness and completion of work is poor

Solution: Set expectations for deliverables and communication, even if these are minimal. Setting expectations allows people to either meet expectations or quit.

Related practices:

- W.7 Reject contributions of insufficient quality is a more SPECIFIC practice.

- W.3 Give permission to quit a task is a COMPLEMENTARY practice.

- W.5 Automate checking the quality of work is a COMPLEMENTARY practice.

- W.8 Mentor to quality is a COMPLEMENTARY practice.

- G.5 Create a community definition of quality is a possible PRECEDING step.

Used by: $\mathrm{CM}_{13}, \mathrm{CM}_{18}, \mathrm{CM}_{24}$

Practice W.7: Reject contributions of insufficient quality

Context: People or companies make inappropriate contributions, or contributions which do not meet the community's quality requirements.

\section{Concerns:}

- 4.C Episodic contributor lacks understanding of project vision

Solution: Decline contributions which are inappropriate or not of sufficient quality. The project will be of higher quality.

Related practices:

-W.6 Set expectations is a more GENERAL practice.

- W.5 Automate checking the quality of work is a COMPLEMENTARY practice.

- W.8 Mentor to quality is a COMPLEMENTARY practice.

- G.5 Create a community definition of quality is a possible PRECEDING step.

- W.9 Require documentation as part of the submission is a possible PRECEDING step.

Challenges: Some people will be discouraged from participating.

Used by: $\mathrm{CM}_{3}, \mathrm{CM}_{5}, \mathrm{CM}_{10}, \mathrm{CM}_{18}, \mathrm{CM}_{24}$ 
Practice W.8: Mentor to quality

Context: Submissions are routinely of insufficient quality.

Concerns:

- 4.C Episodic contributor lacks understanding of project vision

- 5.C Episodic contributor and community have mismatched expectations

- 6.C Episodic contributor quality of work is insufficient

- 7.C Episodic contributor's timeliness and completion of work is poor

- 11.C Community lacks an episodic strategy

Solution: Provide mentoring when contributions are rejected due to insufficient quality. This might include access to tools to help people meet quality requirements. Ensure that contributors can always reach out to mentors to get up to speed. In the long term, teaching people to make quality contributions will result in more quality contributions. Contributors' personal goals of learning and improving are more likely to be met. People who are satisfied may contribute more.

Related practices:

- R.13 Incorporate unofficial successes is a possible ALTERNATIVE step.

-W.6 Set expectations is a COMPLEMENTARY practice.

- W.7 Reject contributions of insufficient quality is a COMPLEMENTARY practice.

- W.10 Encourage learners to mentor is a COMPLEMENTARY practice.

- G.5 Create a community definition of quality is a possible PRECEDING step.

- P.20 Offer a consistent development environment is a possible PRECEDING step.

- W.12 Sever ties is a possible SUCCEEDING step.

Challenges: In the short term, mentoring will cost more time. A cost/benefit analysis may be beneficial.

Used by: $\mathrm{CM}_{3}, \mathrm{CM}_{5}, \mathrm{CM}_{10}, \mathrm{CM}_{13}, \mathrm{CM}_{14}, \mathrm{CM}_{18}, \mathrm{CM}_{23}$, $\mathrm{CM}_{24}$

Proposed by: $\mathrm{CM}_{19}$

Practice W.9: Require documentation as part of the submission

Context: Submissions usually require maintenance for a period of time after they are incorporated.

Concerns:

- 4.C Episodic contributor lacks understanding of project vision

- 6.C Episodic contributor quality of work is insufficient

- 7.C Episodic contributor's timeliness and completion of work is poor

- 10.C Community has difficulty identifying appropriate tasks for episodic contributors

Solution: Require people to sufficiently document their submissions before they are accepted. The submission can be more easily understood and maintained by others.

Related practices:

- P.12 Respond to all submissions is a COMPLEMENTARY practice.

- O.6 Explain the need for maintenance is a COMPLEMENTARY practice.

- P.4 Document general working practices is a possible PRECEDING step.

- R.12 Listen to suggestions is a possible PRECEDING step.

- W.4 Encourage people to quit is a possible SUCCEEDING step.

- W.7 Reject contributions of insufficient quality is a possible SUCCEEDING step.

Used by: $\mathrm{CM}_{14}, \mathrm{CM}_{17}$

Proposed by: $\mathrm{CM}_{19}, \mathrm{CM}_{24}$
Practice W.10: Encourage learners to mentor

Context: Highly active contributors have limited time to mentor episodic contributors.

Concerns:

- 2.C Episodic contributor lacks awareness of opportunities to contribute

- 4.C Episodic contributor lacks understanding of project vision

- 8.C Community's cost of supervision exceeds benefit of episodic contribution

- 11.C Community lacks an episodic strategy

Solution: Engage episodic contributors in leading other episodic contributors. Let them review episodic contributions and mentor episodic contributors. Episodic contributors are likely to understand the concerns and limitations of other episodic contributors. Using returning episodic contributors to lead episodic contributors lets core contributors focus on other areas, and recognizes the competency of returning episodic contributors.

Related practices:

- P.16 Share success stories is a COMPLEMENTARY practice.

- W.1 Have a key contributor responsible is a COMPLEMENTARY practice.

- W.8 Mentor to quality is a COMPLEMENTARY practice.

- R.2 Encourage social connections is a COMPLEMENTARY practice.

- O.1 Learn about the experience, preferences, and time constraints of participants is a possible PRECEDING step.

Used by: $\mathrm{CM}_{2}, \mathrm{CM}_{5}, \mathrm{CM}_{12}, \mathrm{CM}_{13}$

Proposed by: $\mathrm{CM}_{11}, \mathrm{CM}_{16}$

Practice W.11: Explain the context of the contribution

Context: Tasks are recommended to participants.

Concerns:

- 4.C Episodic contributor lacks understanding of project vision

Solution: Explain how a particular task fits within the larger project goals. People can understand the purpose of their work better.

Related practices:

- P.19 Educate sponsoring organizations is a possible ALTERNATIVE step.

- O.6 Explain the need for maintenance is a COMPLEMENTARY practice.

- G.6 Craft a community vision is a possible PRECEDING step.

Challenges: Understanding the larger context requires time that not all episodic contributors are able or willing to give. Not everyone will acquire a broader understanding.

Used by: $\mathrm{CM}_{2}, \mathrm{CM}_{12}, \mathrm{CM}_{13}$

Proposed by: $\mathrm{CM}_{19}$ 


\section{Practice W.12: Sever ties}

Context: A person's behavior has a severe negative impact on the group.

Concerns:

- 7.C Episodic contributor's timeliness and completion of work is poor

Solution: Publicly sever the group's connection to the individual and explain the reasoning. When a toxic person is removed, other people will have more faith in the community.

\section{Related practices:}

- G.6 Craft a community vision is a possible PRECEDING step.

- W.8 Mentor to quality is a possible PRECEDING step.

Challenges: If the decision appears capricious or political, it can damage opinion of the community. This is a serious measure and should not be undertaken lightly.

Used by: $\mathrm{CM}_{3}, \mathrm{CM}_{9}, \mathrm{CM}_{24}$

\section{Practice W.13: Automate process assistance}

Context: Documentation of processes has lead to an unwieldy document that focuses on nuances instead of getting started. People cannot or do not read the documentation. This practice is more applicable to a larger community, as the effort of implementing the solution may not be justified in a small community with fewer contributors.

\section{Concerns:}

- 1.C Episodic contributor lacks knowledge of developments during absences

- 2.C Episodic contributor lacks awareness of opportunities to contribute

- 6.C Episodic contributor quality of work is insufficient

- 10.C Community has difficulty identifying appropriate tasks for episodic contributors

- 11.C Community lacks an episodic strategy

Solution: Consider automation to help people work through the early processes, such as a chat bot or step-by-step interactive site.

Related practices:

- P.4 Document general working practices is a more GENERAL practice.

Challenges: Interactions with automation does not foster personal relationships.

Used by: $\mathrm{CM}_{7}$
E.5 Contributor Retention

Practice R.1: Publicize your release schedule

Context: Releases have a hard deadline. Returning episodic contributors are involved in the project.

Concerns:

- 3.C Community lacks knowledge of availability of episodic contributors

Solution: Publish your development and release schedule and notify contributors of upcoming milestones, to allow them to plan their engagement. Participants may have the option to align their own availability with the schedule.

Related practices:

- G.2 Use longer delivery cycles is a COMPLEMENTARY practice.

- R.14 Rotate focus areas on schedule is a COMPLEMENTARY practice.

Used by: $\mathrm{CM}_{18}$

Proposed by: $\mathrm{CM}_{19}$

\section{Practice R.2: Encourage social connections}

Context: This practice is in the context of an ongoing initiative with a series of tasks.

Concerns:

- 2.C Episodic contributor lacks awareness of opportunities to contribute

- 7.C Episodic contributor's timeliness and completion of work is poor

- 9.C Community cannot retain episodic contributors for sporadic requirements

Solution: Encourage people to work together in a small group to accomplish a task. This might also include groups within a company, who can use a joint contribution to a project as an opportunity for sharing, learning, and mentoring. People can help encourage one another to complete the work. If people feel they belong, they might return even if they are not currently needed.

\section{Related practices:}

- P.11 Send ambassadors to small events is a more SPECIFIC practice.

- R.3 Follow up on contributors is a more SPECIFIC practice.

- W.10 Encourage learners to mentor is a COMPLEMENTARY practice.

- R.4 Instill a sense of community is a COMPLEMENTARY practice.

- G.6 Craft a community vision is a possible PRECEDING step.

- P.11 Send ambassadors to small events is a possible PRECEDING step.

Challenges: Not everyone likes to engage with others; some may prefer working alone

Used by: $\mathrm{CM}_{3}, \mathrm{CM}_{5}, \mathrm{CM}_{13}, \mathrm{CM}_{19}, \mathrm{CM}_{24}$

Proposed by: $\mathrm{CM}_{9}$ 
Practice R.3: Follow up on contributors

Context: There is an initiative where ongoing participation is desired, but episodic contributors are not returning.

Concerns:

- 2.C Episodic contributor lacks awareness of opportunities to contribute

Solution: Keep in touch with contributors, even if just by sending an email. People will appreciate the personal touch and be more likely to return.

\section{Related practices:}

- R.2 Encourage social connections is a more GENERAL practice.

Proposed by: $\mathrm{CM}_{14}$

\section{Practice R.4: Instill a sense of community}

Context: Ongoing participation is desired, but one-off contributions are common.

\section{Concerns:}

- 4.C Episodic contributor lacks understanding of project vision

Solution: Help people to understand the cooperative values that underlie free and open source software. This is best done by leading through example. People with a stronger sense of community are more likely to return to the community.

\section{Related practices:}

- G.6 Craft a community vision is a COMPLEMENTARY practice.

- R.2 Encourage social connections is a COMPLEMENTARY practice.

- R.7 Recognize everyone is a COMPLEMENTARY practice.

Challenges: Not everyone wants to form relationships, some just want to accomplish a task.

Used by: $\mathrm{CM}_{9}$

Proposed by: $\mathrm{CM}_{15}$

\section{Practice R.5: Acknowledge all contributions}

Context: Returning episodic contributors are confused with new contributors, leading to hurt feelings.

\section{Concerns:}

- 16.C Community lacks appreciation for and recognition of episodic contributors

Solution: Have someone responsible for recognizing returning episodic contributors. This person could thank episodic contributors for returning, or, alternately explicitly welcome new contributors. Episodic contributors will be aware that their previous contributions were recognized.

Related practices:

- R.6 Reward participation is a more SPECIFIC practice.

- R.7 Recognize everyone is a more SPECIFIC practice.

Challenges: There needs to be sufficient tooling to track returning episodic contributors

Used by: $\mathrm{CM}_{2}, \mathrm{CM}_{3}, \mathrm{CM}_{5}, \mathrm{CM}_{13}, \mathrm{CM}_{14}, \mathrm{CM}_{19}, \mathrm{CM}_{24}$

Proposed by: $\mathrm{CM}_{4}$
Practice R.6: Reward participation

Context: Extra people are needed for a one-off situation, such as running an event. People participate for self-benefit.

Concerns:

- 2.C Episodic contributor lacks awareness of opportunities to contribute

- 3.C Community lacks knowledge of availability of episodic contributors

- 10.C Community has difficulty identifying appropriate tasks for episodic contributors

Solution: Offer a tangible reward for participation, such as an organizer's dinner or swag. Alternatively, offer recommendation letters, certificates, or online recommendations. More people will be motivated to participate.

Related practices:

- R.5 Acknowledge all contributions is a more GENERAL practice.

- P.11 Send ambassadors to small events is a more SPECIFIC practice.

- R.8 Praise publicly is a more SPECIFIC practice.

- R.7 Recognize everyone is a possible PRECEDING step.

Challenges: People who are motivated by these incentives may require some supervision to perform work at sufficient quality.

Used by: $\mathrm{CM}_{5}, \mathrm{CM}_{13}, \mathrm{CM}_{14}, \mathrm{CM}_{23}, \mathrm{CM}_{24}$

\section{Practice R.7: Recognize everyone}

Context: This practice pertains to returning contributors. It is most applicable to non-code contributions.

Concerns:

- 2.C Episodic contributor lacks awareness of opportunities to contribute

- 10.C Community has difficulty identifying appropriate tasks for episodic contributors

- 16.C Community lacks appreciation for and recognition of episodic contributors

Solution: Make use of systems such as badges to recognize the variety of different contributions people can make. At the conclusion of a cycle, thank and identify contributors. People who make non-code contributions will feel recognized for their work.

Related practices:

- R.5 Acknowledge all contributions is a more GENERAL practice.

- R.8 Praise publicly is a more SPECIFIC practice.

- R.4 Instill a sense of community is a COMPLEMENTARY practice.

- P.10 Keep communication channels active is a possible PRECEDING step.

- R.6 Reward participation is a possible SUCCEEDING step

Challenges: Automating this requires tooling. It is not always easy to generate effective statistics from existing badge systems. If the fairness of the system is not monitored, cheating can occur, which is demotivating.

Used by: $\mathrm{CM}_{2}, \mathrm{CM}_{5}, \mathrm{CM}_{8}, \mathrm{CM}_{10}, \mathrm{CM}_{12}, \mathrm{CM}_{13}, \mathrm{CM}_{14}, \mathrm{CM}_{16}$, $\mathrm{CM}_{18}, \mathrm{CM}_{24}$

Proposed by: $\mathrm{CM}_{4}$ 
Practice R.8: Praise publicly

Context: This practice is most relevant in a situation where there is repeat engagement.

\section{Concerns:}

- 6.C Episodic contributor quality of work is insufficient

Solution: Praise volunteers publicly. People will appreciate the recognition. People will feel more obligation to perform well.

Related practices:

- R.6 Reward participation is a more GENERAL practice.

- R.7 Recognize everyone is a more GENERAL practice.

Used by: $\mathrm{CM}_{3}, \mathrm{CM}_{5}, \mathrm{CM}_{13}, \mathrm{CM}_{18}, \mathrm{CM}_{24}$

Practice R.9: Provide evaluations and a promotion path

Context: Episodic contributors are unable to develop as contributors. There is sustained episodic participation, and absences do not affect the completion of duties.

\section{Concerns:}

- 15.C Community gives episodic contributors reduced access to opportunities and rewards

Solution: Provide assessment and opportunities to episodic contributors. Examples of assessment are skill exploration and personal evaluation. Examples of opportunities are travel, employment consideration, succession planning, and skill building. Sustained episodic participants are encouraged to continue contributing and are more beneficial to the community.

Related practices:

- R.10 Promote episodic contributors is a more SPECIFIC practice.

Used by: $\mathrm{CM}_{13}, \mathrm{CM}_{14}, \mathrm{CM}_{22}$

Proposed by: $\mathrm{CM}_{4}$

\section{Practice R.10: Promote episodic contributors}

Context: There is sustained episodic participation. Absences do not affect completion of duties.

\section{Concerns:}

- 14.C Community excludes episodic contributors from discussions and decisions

Solution: Give sustained episodic participants access to rotating leadership positions which depend on experience rather than continuous contributions. Sustained episodic participants are encouraged to continue contributing. Episodic participants will be able to lead with an understanding of what episodic participation entails.

\section{Related practices:}

- R.9 Provide evaluations and a promotion path is a more GENERAL practice.

- G.4 Make decisions in public is a COMPLEMENTARY practice.

Used by: $\mathrm{CM}_{13}$

Proposed by: $\mathrm{CM}_{14}$
Practice R.11: Announce milestones and celebrate meeting goals

Context: Progress is not always immediately visible.

Concerns:

- 2.C Episodic contributor lacks awareness of opportunities to contribute

Solution: Announce when milestones have been met, and celebrate success. Progress is more visible. Milestones may cause enthusiasm among episodic or new contributors.

Related practices:

- G.6 Craft a community vision is a possible PRECEDING step.

- G.7 Define measuring and success is a possible PRECEDING step.

- P.13 Have a social media team is a possible PRECEDING step.

- G.1 Manage the delivery triangle is a possible SUCCEEDING step.

Challenges:

Used by: $\mathrm{CM}_{3}, \mathrm{CM}_{13}, \mathrm{CM}_{24}$

\section{Practice R.12: Listen to suggestions}

Context: There is a strong separation between leaders and other contributors.

Concerns:

- 4.C Episodic contributor lacks understanding of project vision

- 14.C Community excludes episodic contributors from discussions and decisions

Solution: Allow anyone who participates to propose what want to implement, even if the decisions are ultimately made by a steering committee. If concepts don't fit in with the primary project goals, allow people to create unofficial initiatives, provided these don't damage the project. Also listen to input about the community itself. People will feel more engaged in the community when they can propose ideas.

\section{Related practices:}

- P.4 Document general working practices is a COMPLEMENTARY practice.

- P.1 Identify appropriate tasks is a possible PRECEDING step.

- P.6 List current areas of activity is a possible SUCCEEDING step.

- W.9 Require documentation as part of the submission is a possible SUCCEEDING step.

- R.13 Incorporate unofficial successes is a possible SUCCEEDING step.

Challenges: Care must be taken to prevent a situation where people suggest ideas they expect other people to implement.

Used by: $\mathrm{CM}_{3}, \mathrm{CM}_{6}, \mathrm{CM}_{12}, \mathrm{CM}_{13}, \mathrm{CM}_{18}, \mathrm{CM}_{19}$

Proposed by: $\mathrm{CM}_{1}, \mathrm{CM}_{14}, \mathrm{CM}_{15}, \mathrm{CM}_{23}$ 


\section{Practice R.13: Incorporate unofficial successes}

Context: People are encouraged to take concepts which don't fit in with the project's primary goals and develop them independently. Some independent initiatives are successful and would benefit the project.

\section{Concerns:}

- 4.C Episodic contributor lacks understanding of project vision

- 8.C Community's cost of supervision exceeds benefit of episodic contribution

Solution: Invite creators of unofficial initiatives to incorporate them in the main project if they are successful and of high quality. Alternatively, if the project is stand-alone, recognize these successes within the project. Participants are less likely to feel alienated if trial projects can eventually be included in the main project.

Related practices:

- W.8 Mentor to quality is a possible ALTERNATIVE step.

- R.12 Listen to suggestions is a possible PRECEDING step.

\section{Challenges:}

Used by: $\mathrm{CM}_{12}, \mathrm{CM}_{13}, \mathrm{CM}_{18}$

\section{Practice R.14: Rotate focus areas on schedule}

Context: The work is highly specialized, but multiple specialities are required. It is desirable for episodic contributors to return.

\section{Concerns:}

- 9.C Community cannot retain episodic contributors for sporadic requirements

Solution: Rotate between different focus areas with a consistent schedule. People will be able to plan when their expertise is needed.

\section{Related practices:}

- P.14 Set expiration dates is a COMPLEMENTARY practice.

- R.1 Publicize your release schedule is a COMPLEMENTARY practice.

- O.1 Learn about the experience, preferences, and time constraints of participants is a possible PRECEDING step.

Used by: $\mathrm{CM}_{15}, \mathrm{CM}_{18}, \mathrm{CM}_{19}$
"Most of the time; the most common mistake we have made is to recruit volunteers from everywhere. Whereas open selection is great, some communities perform better when you target places or other communities where the exact people you need can be found and with similar interests."

$-C M_{13}$

\section{APPENDIX F \\ WORKFLOWS}

Workflows are relationships which have been proposed as a collection of practices by a community manager. Below are the workflows proposed by our participants, showing concurrent COMPLEMENTARY practices and sequential practices. The PRECEDING/SUCCEEDING sequence is depicted with an arrow, while COMPLEMENTARY practices can be inferred when they connect to the same succeeding practice. In some cases (e.g., Fig. 10), the community manager proposed to execute several practices more or less simultaneously, without any subsequent steps. Such diagrams contain no arrows.

Figure 9 shows the inclusion of a practice which was not part of this study, depicted in light gray. Please refer to the original paper for an explanation of the decision to exclude recruitment-specific practices. Recruit in the right places is the practice of advertising the project in relevant places, where people might be expected to be interested in the community's goals. It is illustrated by this quote: 


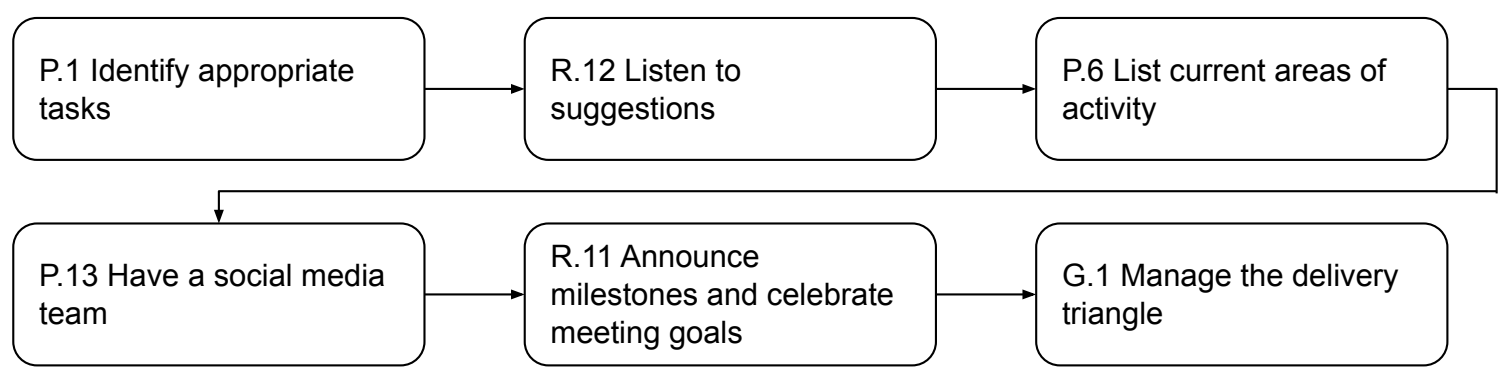

Fig. 1. Possible workflow to address concern 2.C Episodic contributor lacks awareness of opportunities to contribute $\left(\mathrm{CM}_{3}\right)$

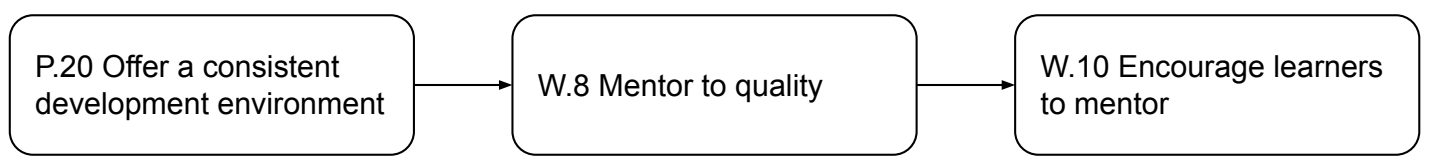

Fig. 2. Possible workflow to address concern 2.C Episodic contributor lacks awareness of opportunities to contribute $\left(\mathrm{CM}_{11}\right)$

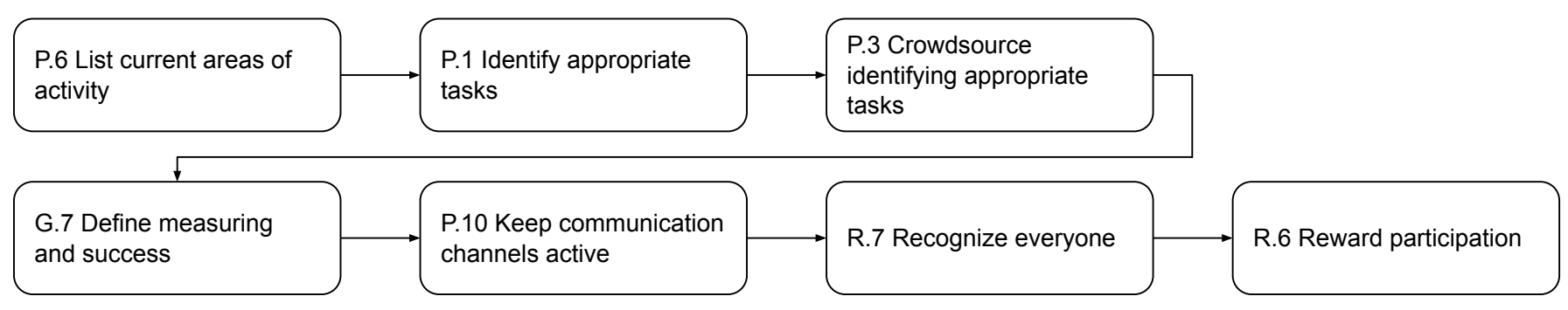

Fig. 3. Possible workflow to address concerns 2.C Episodic contributor lacks awareness of opportunities to contribute and 10.C Community has difficulty identifying appropriate tasks for episodic contributors $\left(\mathrm{CM}_{5}\right)$

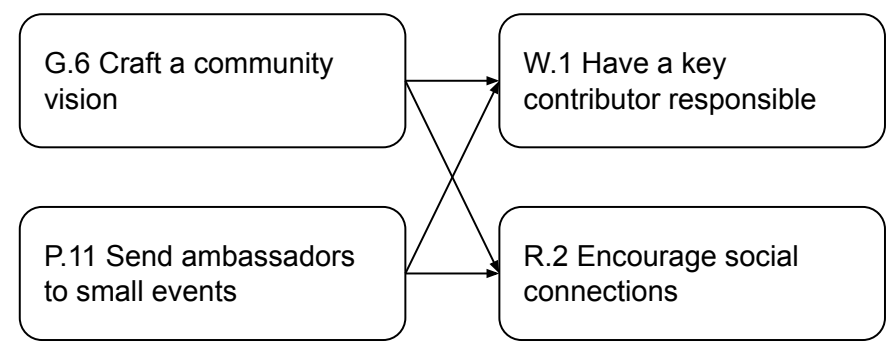

Fig. 4. Possible workflow to address concerns 2.C Episodic contributor lacks awareness of opportunities to contribute and 4.C Episodic contributor lacks understanding of project vision $\left(\mathrm{CM}_{9}\right)$

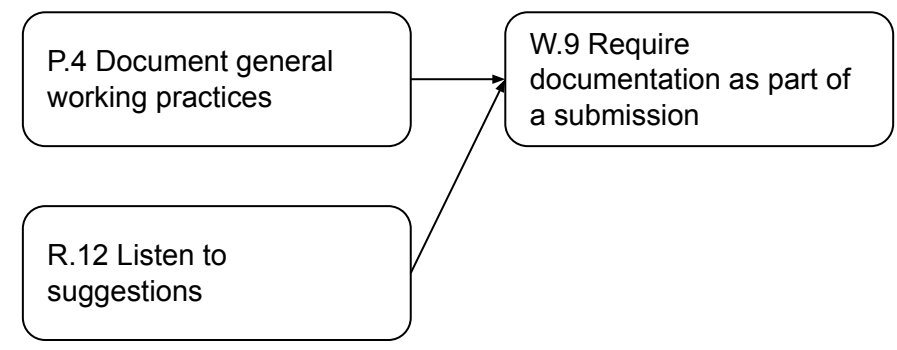

Fig. 5. Possible workflow to address concern 6.C Episodic contributor quality of work is insufficient $\left(\mathrm{CM}_{24}\right)$ 


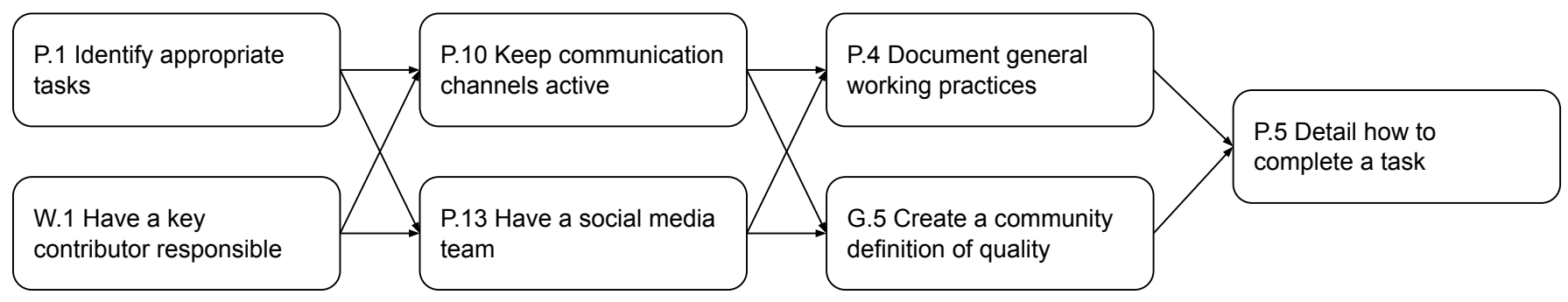

Fig. 6. Possible workflow to address concern 11.C Community lacks an episodic strategy $\left(\mathrm{CM}_{6}\right)$

G.7 Define measuring
and success

P.1 Identify appropriate
tasks

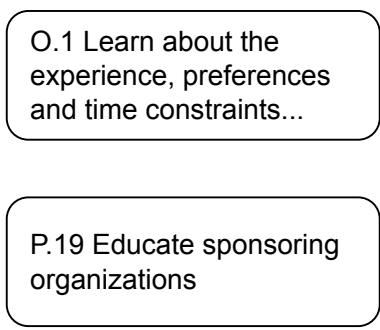

P.15 Create continual points of entry

Fig. 7. Possible workflow to address concern 11.C Community lacks an episodic strategy $\left(\mathrm{CM}_{17}\right)$

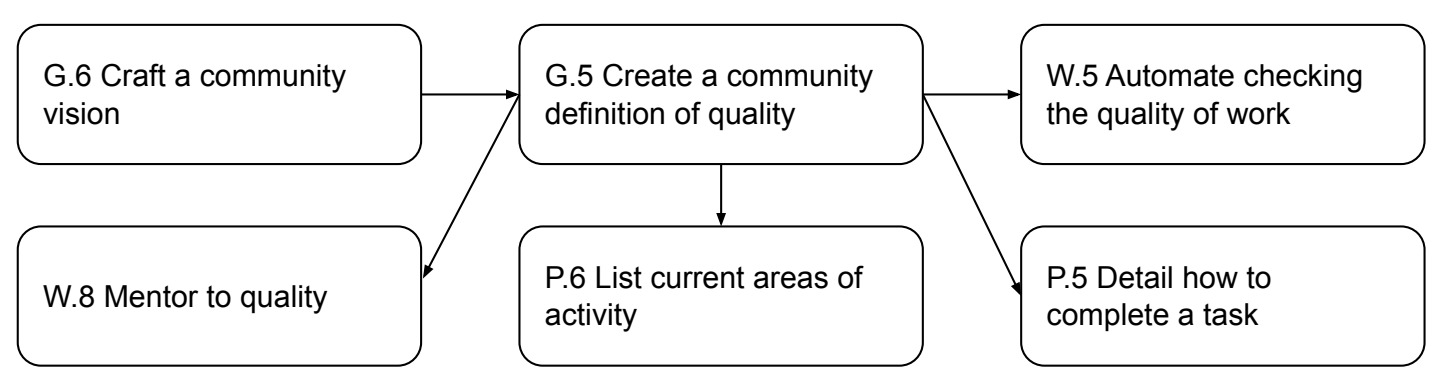

Fig. 8. Possible workflow to address concern 11.C Community lacks an episodic strategy $\left(\mathrm{CM}_{19}\right)$

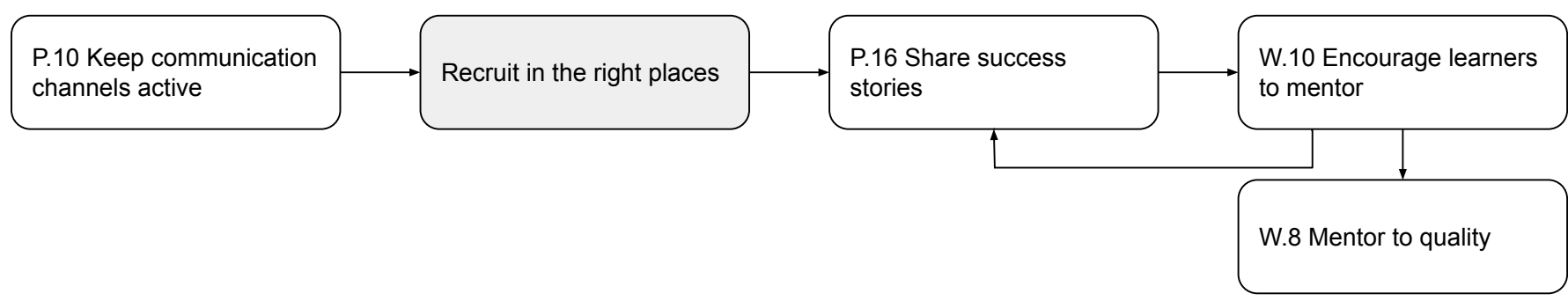

Fig. 9. Possible workflow to address concern 4.C Episodic contributor lacks understanding of project vision $\left(\mathrm{CM}_{13}\right)$

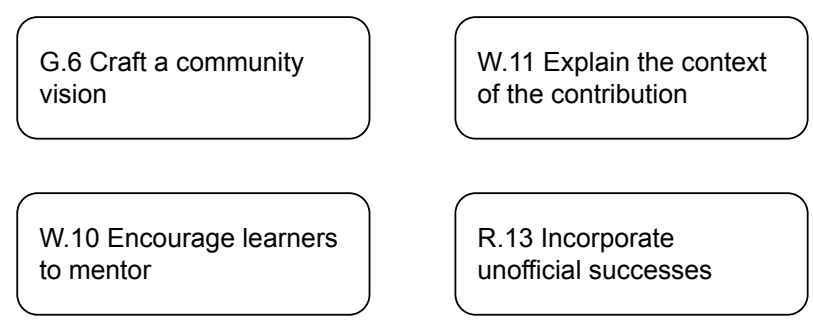

\section{R.12 Listen to suggestions}

Fig. 10. Possible workflow to address concern 4.C Episodic contributor lacks understanding of project vision $\left(\mathrm{CM}_{12}\right)$ 


P.5 Detail how to
complete a task

P.4 Document general
working practices

P.10 Keep communication channels active
P.1 Identify appropriate tasks

Fig. 11. Possible workflow to address concern 5.C Episodic contributor and community have mismatched expectations $\left(\mathrm{CM}_{7}\right)$ 